\title{
A closer look at an eroded dune landscape: first functional insights into the Federmessergruppen site of Lommel-Maatheide
}

Sonja Tomasso ${ }^{1 *}$, Dries Cnuts ${ }^{1 *}$, Justin Coppe ${ }^{1}$, Marijn Van Gils ${ }^{2}$, Ferdi Geerts 3 , Marc De Bie ${ }^{4}$, Veerle Rots $^{1,5}$

Affiliations:

${ }^{1}$ TraceoLab/ Prehistory, University of Liège, Belgium

${ }^{2}$ Flanders Heritage Agency

${ }^{3}$ Museum De Kolonie, Lommel

${ }^{4}$ Flanders Heritage Agency and Vrije Universiteit Brussel

${ }^{5}$ Maître de recherches du FNRS, Belgium

*Contributed equally to the publication

\begin{abstract}
The vast Federmessergruppen site of Lommel-Maatheide, which is located in the Campine region (Northern Belgium), revealed the presence of numerous Final Palaeolithic concentrations situated on a large Late Glacial sand ridge on the northern edge of a contemporary lake. This situation offers a unique possibility for a large-scale functional analysis in order to understand the occupation of such a Late Glacial dune landscape. The variable preservation state of the lithic artefacts permitted to evaluate in detail the impact of post-depositional processes on the potential of functional studies. Also, the impact of excavation protocols on the preservation of wear traces and residues was evaluated, in particular the impact of mechanical sieving. The integrated functional research that included the microscopic examination of wear traces, fractures and residues, next to experimentation, permitted the identification of a range of crafting and hunting activities, thereby demonstrating the potential of such assemblages for obtaining innovative insights into Late Glacial site dynamics in spite of a varying preservation state.
\end{abstract}

Keywords: use-wear analysis, residues, excavation protocols, projectiles, experiments, Final Palaeolithic, Federmessergruppen

\section{Introduction}

Functional analysis is known to contribute important insights in tool use and site function (e.g. Beugnier and Crombé 2005; De Bie and Caspar 2000; Guéret et al. 2014) and most functional studies performed up to now have focused on rather well-preserved site contexts within 
restricted areas (e.g. Guéret 2017; Van Noten 1978), in particular when the Final Palaeolithic period is concerned. If such studies are coupled with refitting studies and spatial analysis, they provide unique and highly detailed glimpses into site dynamics, as abundantly illustrated for Federmessergruppen assemblages (Cahen et al. 1979; De Bie and Caspar 2000; Van Noten 1978). Indeed, the first study that integrated use-wear, refitting and spatial analysis was performed at the Federmessersite of Meer (Belgium), a site of 0,04 ha (Cahen et al. 1979; Van Noten 1978). At Rekem (Belgium), an extensive use-wear and refitting study on 2500 lithics across 1.7 ha unveiled a large variety of activities, including both domestic (De Bie and Caspar 1997, 2000; De Bie and Van Gils 2006) and hunting activities (Caspar and De Bie 1996). Extensive spatial analysis, made possible by the careful excavation and individual mapping of these artefacts, led to the reconstruction of the chain of activities that took place and enabled the identification of different working areas within this Late Glacial settlement. These studies have thus proven the potential of functional analysis for reconstructing settlement patterns in the case of relatively restricted surface areas and the availability of fine-grained spatial data.

The potential of functional analysis in reconstructing tool use and spatial patterns is less clear when it comes to assemblages that are spread over vast surfaces and when available contextual data are less fine-grained. One may assume that if the quality of the functional data is sufficiently detailed for each of the concentrations that such contexts have great potential for addressing technology, subsistence strategies, including hunting and domestic tasks, as well as for addressing broader questions on land use, in particular when specific landscapes are concerned. The quality and availability of functional data may, however, be biased by differential preservation between the concentrations as the intensity and nature of post-depositional processes can differ depending on the exact location of the concentration and its burial history. Adequately understanding how taphonomy may impact the preservation of wear traces, fractures and residues thus remains an important issue to address in functional analysis in order to fully grasp the analytical potential.

Several experimental studies have shown the impact of a particular post-depositional process on wear traces (e.g. Tringham et al., 1974; Rottländer, 1975; Stapert, 1976; Levi Sala, 1988; Plisson and Van Gijn, 1989). Mechanical alterations may be caused by processes such as trampling, movement in the soil, erosion by wind and water and consist of macroscopic (e.g. edge rounding, edge scarring, fractures) and/or microscopic modifications (e.g. striations, friction marks) (e.g. Asryan et al. 2014; Burroni et al. 2002; Michel et al. 2019; Newcomer 1976; Sala 1986; Thiébaut 2007). Chemical processes, such as those related to soil chemistry or weathering, may alter or obliterate wear traces, as these processes may lead to surface patination, gloss or polish formation (Asryan et al. 2017; Plisson and Mauger 1988; Rottländer 1975). Also, thermal modifications, being the result of (unintentional) exposure to heat or freeze-thaw actions, have to be taken into account when evaluating post-depositional wear and other wear (e.g. Cnuts, Tomasso, et al. 2018; Michel et al. 2019). While the impact of post-depositional processes on 
wear traces is known to a certain extent, this is less the case for how they affect the preservation of residues. Understanding residue preservation is quite complex as the chemical and structural composition of residues varies greatly and this proves to be a crucial factor in determining their resistance when exposed to post-depositional processes. Recent experimental work has focused mainly on biodegradation in burial contexts (e.g. Croft et al. 2016; Langejans 2010), but other processes such as exposure to heat (Cnuts, Tomasso, et al. 2018), freeze-thaw actions (Michel et al. 2019) or water flow (Cnuts and Rots 2018) have shown to be of significance as well.

Also, excavation protocols may affect the quality of functional data but its exact impact is not well-studied and no clear guidelines for excavators to rely on are available. When large surface areas are excavated, mechanical equipment is often used, which is assumed to severely damage lithic artefacts. The fact that excavation may lead to metal-induced wear on stone tools is known, but the specific situations in which this happens and how this can be avoided best was never systematically explored. Only one experimental study deals with the impact of sieving on the preservation of stone tool surfaces but it consisted of two flint flakes only (Gero 1978). In terms of cleaning, the impact of chemicals on wear trace preservation has been demonstrated in the past and has helped to define strict cleaning protocols (e.g. Plisson 1985; Plisson and Mauger 1988). For residues, handling and cleaning protocols are even more crucial. It is generally assumed (e.g. Fullagar et al. 2006; Hardy 2004; Lampert and Sim 1986) that cleaning may remove ancient residues, which is one of the reasons why washing of finds is generally counter-advised. A strict protocol does not exist, however, though propositions have been made (Cnuts 2021). Handling is known to leave finger grease that may be difficult to remove (Pedergnana et al. 2016; Rots et al. 2016) and experimental work has shown that contamination from handling may lead to misinterpretation (Rots et al. 2016). It has been suggested that manipulation with starch-free gloves is essential to avoid such residues (Hayes and Rots 2019; Cnuts 2021).

The central goal of the functional study was thus to evaluate to what extent this type of variably preserved site could still contribute to the understanding of Federmessergruppen technology and organization, with particular attention to the impact of taphonomy and excavation protocols, and an identification of domestic and hunting tasks. This evaluation includes five research objectives: (1) to evaluate the influence of differential preservation conditions on the kind of functional inferences that can be proposed; 2 ) to improve insight in which excavation protocols affect the preservation of wear traces and residues the least; (3) to evaluate what domestic tasks can be identified and to what extent preservation biases functional insights; (4) to identify the potential of the site for identifying hunting activities and the propulsion mode used; and (5) to evaluate whether a specific function can be proposed for each concentration and to what extent functional analysis improves our understanding of Federmessergruppen lifeways. The site of Lommel-Maatheide offers unique potential in this regard thanks to the exceptionally large surface area of the site (45ha) with numerous artefact concentrations, the broad variation in preservation states between the different concentrations 
and the varying excavation strategies used, including the intense sieving that was performed at the site. Stone tool surfaces and edges, as well as residues, can thus be expected to be variably affected.

\section{Site}

Lommel-Maatheide is an extensive site in the Campine region (NE Belgium) that consists of both Final Palaeolithic (Federmessergruppen) and Mesolithic occupations (De Bie et al. 2009). The Federmessergruppen artefact concentrations, studied in this article, are located near a contemporary shallow lake, mostly on a large Late Glacial sand ridge close to its northern edge (cf. Figure 1). The recovered assemblages were entirely made out of flint and witness an elaborate laminar production and three main tool groups typical of the Federmessergruppen of the Campine region (De Bie and Van Gils 2006) could be identified: laterally modified laminar pieces ("Federmesser points"), endscrapers and burins. Also, a respectable number of borers and becs were retrieved.

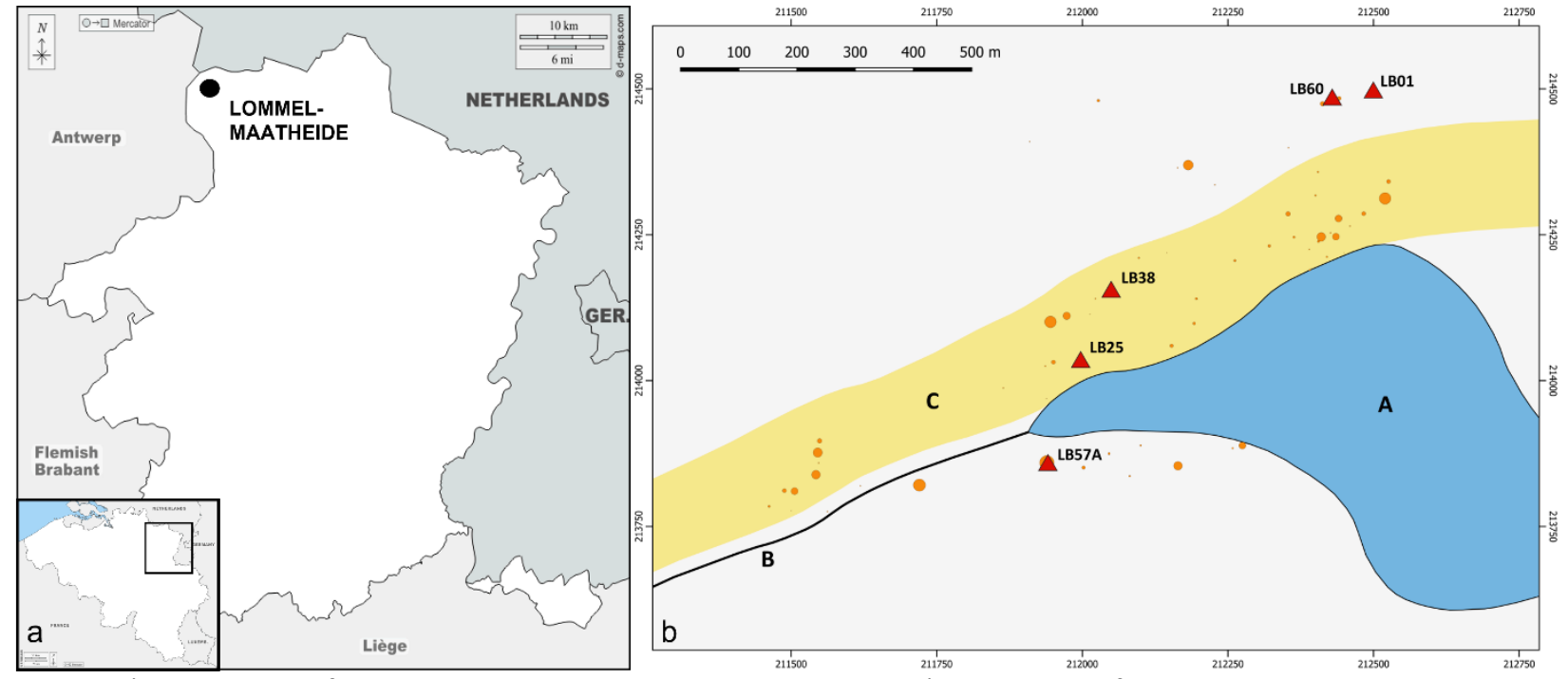

Figure 1 a) The location of Lommel-Maatheide within Northern Belgium. b) Distribution of the concentrations included in this study (surface area of 45ha) and their location within the Late Glacial landscape: shallow lake (A); Rietrijenloop (B); Late Glacial dune (C).

The location has long been known as a rich find spot for Final Palaeolithic (and Mesolithic) artefacts (Creemers and Carolus 1989; Geerts 1984; Hamal-Nandrin et al. 1935; Verheyleweghen 1956; Vermeersch 1975). In the first half of the 20th century, zinc smelting activities destroyed the vegetation cover and initiated wind erosion of the sandy soil (Derese et al. 2012) which caused tens of thousands of artefacts to resurface (De Bie et al. 2009). Many amateur archaeologists visited the location repeatedly to collect artefacts (collection Caris and collection Janssens). During the 1970s, the area was used as a dumping ground to prevent further soil erosion but this was remediated in 2004 to prepare the area for sand exploitation. As the area became under threat of destruction, yearly field campaigns (De Bie et al. 2009; Geerts et al. 2008; Van Gils and 
De Bie 2004, 2005, 2008) were carried out from 2003 until 2008 to detect and recover stone tool artefacts that were still preserved in situ.

A systematic survey of the area revealed the presence of 70 surface concentrations on the (former) ridge north of the valley, with some minor concentrations located in a preserved Usselo soil (De Bie et al. 2009; De Bie and Van Gils 2004) (dated with OSL between 13.5 and $11.3 \pm 0.8 \mathrm{ka}$ BP (Derese et al. 2012). Of particular interest here is the fact that excavations of several concentrations showed that their preservation state is quite variable, depending on their location within the ancient topography. Concentrations located on top of the ridge, such as LB25 and LB38, proved to be heavily affected by deflation during the Younger Dryas and by the podsolisation process during the Holocene. Concentrations in lower topographical positions (LB01, LB60 and LB57A) were covered by aeolian sands during the Younger Dryas and largely protected from later soil formation processes and bioturbation.

Most concentrations were excavated according to a 50 by $50 \mathrm{~cm}$ grid cell system. The majority of concentrations were dry sieved with a motorised swing sieve while a minority was subjected to other sieving strategies. LB01 was partly excavated by detailed troweling because of its conservation in a clear and undisturbed Usselo soil, with part of its artefacts staying clear of any sieve. The stone tools were subsequently washed individually by hand with tap water and a toothbrush, labelled with ink but not covered in any varnish, and refits were glued together. An important part of the curved backed points, being part of a surface collection (Caris \& Janssens), were not sieved but washed by hand. Most of the points were then labelled with ink on a small strip of varnish that was applied on the ventral side of the artefacts.

\section{Materials and methods}

\subsection{Materials}

\subsubsection{Screened artefacts}

The studied artefacts derive from the five concentrations (cf. Table 1) Fout! Verwijzingsbron niet gevonden.that could be attributed with high certainty to the Federmessergruppen: LB01, LB60, LB38, LB25 \& LB57A. These concentrations are located within different areas of the paleolandscape, enabling the study of possible differential preservation between these concentrations and an assessment of the extent to which the functional results are biased by the preservation state.

The total lithic assemblage of the five concentrations consists of 12234 artefacts, from which 770 artefacts (6\%) were selected for a functional screening. Selection criteria were guided by the objectives of the study and in order to adequately evaluate the impact of post-depositional processes and excavation protocols, an appropriate balance was aimed for between unretouched (37\%; $N=280)$ vs. retouched (62\%; $N=473)$ artefacts, large $(90 \% ; N=671)$ vs. small $(10 \% ; N=82)$ artefacts as these categories may respond differently. 


\begin{tabular}{cccc}
\hline Concentration & $\begin{array}{c}\text { Estimated surface } \\
\text { area }\end{array}$ & Total $\mathbf{N}^{\circ}$ of lithics & Screened artefacts \\
\hline LB01 & $32 \mathrm{~m}^{2}$ & 1306 & $44(3 \%)$ \\
LB25 & $252 \mathrm{~m}^{2}$ & 7329 & $389(5 \%)$ \\
LB38 & $30 \mathrm{~m}^{2}$ & 173 & $28(16 \%)$ \\
LB57A & $39 \mathrm{~m}^{2}$ & 2559 & $236(9 \%)$ \\
LB60 & $72 \mathrm{~m}^{2}$ & 867 & $73(8 \%)$ \\
\hline Total & & 12234 & $\mathbf{7 7 0 ~ ( 6 \% )}$ \\
\hline
\end{tabular}

Table 1 Artefacts screened for functional and other evidence per concentration

This selection strategy may have created some bias in terms of the functional understanding of the concentrations as not all potentially used stone tools were necessarily screened. It has to be noted, for instance, that among the formal tool categories, burins are significantly underrepresented $(28 / 139 ; 20 \%)$ while becs $(0 / 17)$ and perforators $(0 / 8)$ are absent. By contrast, all curved backed points $(N=254 ; 100 \%)$ and the majority of endscrapers $(90 / 101 ; 90 \%)$ were screened. The poor preservation state of the material from LB25 (the concentration with most formal tools) led to a preferential selection of endscrapers in comparison to burins as the usewear on the former proved to be still visible whereas this was rarely the case for the latter. For concentration LB01, LB57A and LB60, a first selection was made by the responsible archaeologist; a selection that was further restricted or expanded upon depending on the preservation state of the material within the context of this study (Table 2). For concentration LB25 and LB38, the selection was directly performed by the functional analyst with a specific focus on an adequate evaluation of the potential of the material and thus taking into account preservation states.

Given that one of the objectives of the study specifically focused on hunting technology, all curved backed points $(\mathrm{N}=254)$ were selected in order to verify a possible use as projectile element. In addition, particular focus concerned the large concentration of LB25, the area on the top of the dune, because curved backed points were present in appreciable numbers, in particular when both artefacts from recent excavations and from older surface collections were included. The surface collections consisted of points exclusively and the material was collected during surveys of amateur archaeologists in the area of LB25 (167 curved backed points derive from the Caris collection, and 87 derive from the Janssens collection). Given the very high correspondence in morphology and morphometry, both assemblages were considered here as a homogeneous collection. Their large number permitted to not just evaluate their possible use as a projectile, but also to perform a pilot study with regard to the propulsion mode that may have been used. 


\begin{tabular}{|c|c|c|c|c|c|c|c|c|c|c|c|c|c|c|}
\hline & \multirow[b]{2}{*}{ Artefact type } & \multicolumn{3}{|c|}{ LB01 } & \multicolumn{2}{|c|}{ LB25 } & \multicolumn{2}{|c|}{ LB38 } & \multicolumn{3}{|c|}{ LB57A } & \multicolumn{3}{|c|}{ LB60 } \\
\hline & & $T$ & A & $S$ & $\mathbf{T}$ & $S$ & $T$ & $S$ & $T$ & A & S & $T$ & A & $S$ \\
\hline debitage & $\begin{array}{c}\text { core } \\
\text { core rejuvenation } \\
\text { products } \\
\text { fragment } \\
\text { flake } \\
\text { chip } \\
\text { blade (fragment) } \\
\text { bladelet } \\
\text { laminar* }\end{array}$ & $\begin{array}{l}483 \\
713\end{array}$ & $\begin{array}{c}17 \\
4\end{array}$ & $\begin{array}{l}9 \\
9\end{array}$ & $\begin{array}{c}276 \\
67 \\
2372 \\
2161 \\
376 \\
527 \\
919\end{array}$ & 1 & 12 & 12 & $\begin{array}{c}38 \\
1066 \\
625 \\
439 \\
220 \\
66\end{array}$ & $\begin{array}{c}39 \\
13 \\
2 \\
9\end{array}$ & $\begin{array}{c}9 \\
19 \\
\\
131 \\
2 \\
21\end{array}$ & $\begin{array}{c}326 \\
365 \\
4 \\
114\end{array}$ & $\begin{array}{c}19 \\
4\end{array}$ & $\begin{array}{l}5 \\
61\end{array}$ \\
\hline tools & $\begin{array}{c}\text { endscraper } \\
\text { burin } \\
\text { backed bladelet } \\
\text { curved backed point } \\
\text { point } \\
\text { perforator } \\
\text { bec } \\
\text { truncation } \\
\text { random retouch } \\
\text { retouched flake } \\
\text { retouched blade } \\
\text { tool fragment }\end{array}$ & 10 & 6 & 5 & $\begin{array}{c}77 \\
125 \\
21 \\
254 \\
1 \\
5 \\
14 \\
31 \\
13 \\
12 \\
7 \\
32\end{array}$ & $\begin{array}{c}67 \\
23 \\
21 \\
254 \\
1 \\
4 \\
\\
10 \\
6\end{array}$ & $\begin{array}{l}1 \\
\\
5 \\
1\end{array}$ & $\begin{array}{l}1 \\
1\end{array}$ & $\begin{array}{c}22 \\
4 \\
8 \\
12 \\
4 \\
3 \\
3 \\
4 \\
22 \\
6 \\
3 \\
2\end{array}$ & $\begin{array}{c}2 \\
\\
8 \\
12\end{array}$ & $\begin{array}{c}22 \\
1 \\
12\end{array}$ & $\begin{array}{l}7 \\
8\end{array}$ & $\begin{array}{l}3 \\
7 \\
1\end{array}$ & \\
\hline $\begin{array}{c}\text { tool } \\
\text { waste } \\
\text { products }\end{array}$ & $\begin{array}{l}\text { burin spall } \\
\text { microburin } \\
\text { Krukowski } \\
\text { microburin }\end{array}$ & 2 & 14 & 1 & $\begin{array}{c}35 \\
2\end{array}$ & & & & 4 & & 1 & 17 & 15 & 2 \\
\hline hammer & & & & & & & & & 1 & & 1 & & & \\
\hline ind. & & & & & 2 & 2 & 151 & 10 & 7 & & 7 & 10 & & 1 \\
\hline Total & & 1306 & 61 & 44 & 7329 & 389 & 173 & 28 & 2559 & 89 & 236 & 867 & 74 & 73 \\
\hline
\end{tabular}

Table 2 Overview of the total number of lithics $(T)$, lithics selected by the archaeologist $(A)$, number of lithics screened for functional evidence (S)

\subsubsection{Selected artefacts for functional analysis}

From the 770 selected lithics, a total of 155 artefacts with a sufficient state of preservation and potential use-wear were retained for a more detailed functional analysis (cf.Table 3). None of the 73 screened lithics of LB60 showed potential for use-wear, so only four of the five concentrations (LB01, LB25, LB38, LB57A, and LB60) are represented in the final selection. The majority of the selected artefacts (77\%) are from concentration LB25, given its size and the large number of formal tools in the initial selection for screening. The material that was analysed in 
detail is largely dominated by curved backed points (46\%) and endscrapers (42\%) but also includes a small number of burins, (retouched) flakes, blades, perforators and one backed bladelet.

\begin{tabular}{|c|c|c|c|c|c|c|}
\hline Lithic type & $\angle B 01$ & $\angle B 25$ & $L B 38$ & LB57A & $\angle B 60$ & Total \\
\hline Screened artefacts & 44 & 389 & 28 & 236 & 73 & 770 \\
\hline $\begin{array}{l}\text { Selected for detailed } \\
\text { analysis (\% of } \\
\text { screened artefacts) }\end{array}$ & $5(11 \%)$ & $116(29 \%)$ & $2(7 \%)$ & $32(14 \%)$ & 0 & 155 \\
\hline endscraper & & 39 & 1 & 16 & & 56 \\
\hline retouched flake & & & & 3 & & 3 \\
\hline burin & 5 & 1 & & & & 6 \\
\hline flake & & & 1 & 1 & & 2 \\
\hline blade & & & & 2 & & 2 \\
\hline perforator & & 2 & & & & 2 \\
\hline backed bladelet & & & & 1 & & 1 \\
\hline curved backed point & & 74 & & 9 & & 83 \\
\hline
\end{tabular}

\subsection{Methods}

\subsubsection{Screening}

Stone tools $(n=770)$ were screened with a Zeiss stereomicroscope Discovery.V12 (oblique external light source, magnifications up to $\times 100$ ) and a Zeiss Macro-Zoom Microscope V16 (oblique external light source, magnifications up to 180x), to evaluate the state of preservation and to detect potential residues and use-wear. During analysis, artefacts were handled with gloves and cleaned with ethanol to remove finger grease resulting from previous handling.

The macroscopic screening permitted a comprehensive view of the state of preservation of the assemblage (cf. Table 4), an assessment of the impact of the excavation strategy, and an evaluation of the differences in taphonomic surface alteration between the loci.

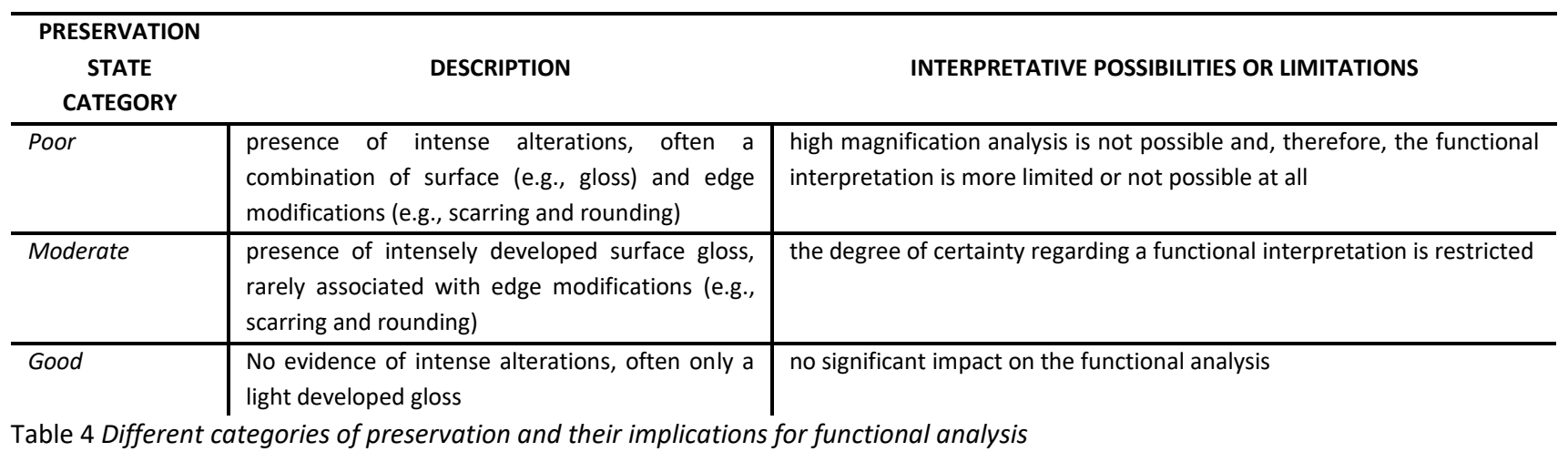




\subsubsection{Functional analysis}

\subsubsection{Use-wear analysis}

Functional wear traces were recorded according to standard methodological protocols applied in use-wear studies (e.g. Grace 1990; Kamminga 1979; Keeley 1980; George H. Odell 1981; Rots 2002; Stordeur 1987; Tringham et al. 1974; Vinet and Zhedanov 2011). These functional traces not only included use-related traces but also potential hafting (Rots 2002, 2003, 2010a) and production (Rots 2010b) wear patterns were recorded. Use-wear analysis was performed with both stereo- (Zeiss stereomicroscope Discovery.V12 (oblique external light source, magnifications up to $\times 100$ )) and incident light microscopic analysis (Zeiss or Olympus metallurgical reflected-light microscope (magnifications $\times 50-\times 1000$ ), equipped with polarising filters and DIC) to obtain an accurate view on all forms of wear in order to permit reliable identification of the contact material (e.g. Keeley 1980; George Hamley Odell and Odell-Vereecken 1980; Tringham et al. 1974).

The analysis of the macro- and microscopic evidence was systematically verified with experimental examples from the TraceoLab's reference collection (TRAIL). The confidence with which traces on an archaeological stone tool can be interpreted varies depending on the preservation state of the surfaces (i.e. intensity of post-depositional alteration), on the development of the traces and the presence/absence of diagnostic wear features and patterning. Therefore, each interpretation was scored on a scale of 0 (uncertain), 1 (poor confidence), 2 (moderate confidence), 3 (high confidence), to 4 (certain). This is part of the standard analytical protocol in use at TraceoLab (also highlighted in Rots 2010a).

\subsubsection{Residue analysis}

Stone tool residues were observed with stereo- and incident light microscopy, which allowed recording crucial attributes for distinguishing between modern contamination, environmental and cultural residues, such as the location of the residue on the tool, the presence of smearing, directionality and association with use-wear (Cnuts, Tomasso, et al. 2018; Cnuts 2021; Cnuts and Rots 2018; Rots et al. 2016). Optical microscopy allowed to identify visually distinctive residues (e.g. plant tissue, feathers, feather barbules) (Croft et al. 2016), while other residues required additional characterization with elemental analysis (SEM-EDS) (Hayes et al. 2019; Hayes and Rots 2019; Pedergnana and Ollé 2017). Here, residue analysis focused on identifying the whole range of cultural residues that may adhere to the stone tool surface and may include residues from tool use, hafting, and production (Cnuts 2021; Fullagar 2006; Fullagar and Matheson 2014; Rots et al. 2016). Interpretations relied on reference material available at TraceoLab (TRAIL). 


\subsubsection{Projectile analysis}

All curved backed points were examined for possible projectile evidence with a Zeiss stereomicroscope Discovery.V12 (oblique external light source, magnifications up to $\times 100$ ). The attributes of the observed fractures were described in detail following the terminology (proposed in Coppe and Rots 2017). Fractures consisted of three categories: bending breaks, secondary damage, lateral scars. Curved backed points were identified as weapon elements if at least a combination of two fractures (breaks or scars) caused by an axial stress were present.

- The first category (bending breaks) includes all breaks initiated in bending from a surface or an edge and terminating on the surface or the opposite edge independent of the type of termination. Bending breaks can be used as evidence for compressive stress when they present long propagation phases, fissured terminations and an association with secondary damage.

- The second category (secondary damage) is composed of scars (regardless of the morphology of their initiation) initiated from the surface of a pre-existing bendinginitiated fracture and terminating on a surface or an edge (all types of termination). These fractures are caused by a stress that involved a bending and a compressive component which creates an initial bending break on which a strong compressive component is applied. The latter generates one or more scars whose initiations can be cone, bending or intermediate depending on the resistance of the edge on which they form. The presence of secondary damage strengthens the identification of weapon elements, in particular when multiple scars are produced at the same time from their initial bending break, when scars present destroyed initiations, fissured terminations and long propagation phases.

- The third category (lateral scars) includes all scars initiated from a surface, independent of the type of initiation, that terminate on the opposite surface and exhibit the same orientation (oblique or perpendicular to the axis of the point). Lateral scars can be used as evidence for compressive stress when multiple scars are present and when they show oblique orientations, destroyed initiations, fissured terminations, and secondary damage on their termination.

Methods for identifying the propulsion mode are still under development (Coppe 2020), but important elements have been put forward over the last years (e.g. (Coppe et al. 2019; Coppe and Rots 2017). At the moment, evaluations of the propulsion mode can only be attempted under strict conditions, including the necessity of a sufficiently large number of pieces with a uniform morphology and raw material in order to permit an examination of the broader patterning. For the site of Lommel-Maatheide, this is only the case for locus LB25. An evaluation of the propulsion mode further needs to rely on an experimental program in which the morphology and size of the archaeological points are reproduced, preferably in the same raw material. In the light of this pilot test case, an experimental set of 30 points was thus created, hafted and shot into an artificial animal target. Details are discussed in section 5.4.2. In addition, the analysis relied on the TraceoLab experimental reference collection TRAIL (Coppe 2020; Rots 2021; see below). 


\subsubsection{Reference collection TRAIL}

Functional interpretations were based on comparisons with TRAIL, the TraceoLab experimental reference collection. Currently, the TRAIL comprises $\sim 5800$ experimental artefacts (for details see Rots 2021). TRAIL can be considered representative for a broad range of trace causes, including production (Rots 2010b), hafting (Rots 2002, 2010a) and tool use (Rots 2002; Taipale 2020; Taipale and Rots 2021; Tomasso 2021). TRAIL also integrates a large number of projectiles used with different propulsion modes (e.g., Coppe 2020; Coppe and Rots 2017; de la Peña et al. 2018; Lepers and Rots 2020; Taipale and Rots 2019; Tomasso et al. 2018) and experimental tools from experiments focused on taphonomic processes (e.g., Cnuts, Tomasso, et al. 2018; Michel et al. 2019) and post-excavation procedures, such as sieving or storage (Cnuts 2021; Rots 2010a). TRAIL also contains a library for residues, with 500 residue samples and a large number of tools specifically devoted to this topic (e.g., Cnuts 2021; Cnuts and Rots 2017, 2018; Hayes et al. 2019; Hayes and Rots 2019).

TRAIL also integrates several blind tests, focused on wear traces and residues (e.g., Coppe 2020; Genevois 2019; Hayes et al. 2017; Rots et al. 2006, 2016; Taipale 2020; Tydgadt 2019).

\section{Results}

\subsection{Influence of post-depositional processes on preservation state}

The systematic screening under a stereoscopic microscope revealed differential preservation between the concentrations and varying alteration degrees of the artefact surfaces appears to reflect a differing taphonomical history for each of the concentrations (Figure 2). The majority of the LB01 artefacts display a good preservation state with only a light surface gloss, but a minor part of the artefacts proved to be heat-altered (Figure 2f), which had resulted in light or heavy patination. The lithics of LB60 show similar macroscopic preservation, but the majority of the artefacts display a moderate to heavy gloss on their surfaces under magnification with a minor part of the artefacts also showing rounded edges/ridges and/or patination. The sample of LB57A shows a more diverse preservation pattern with one quarter being poorly preserved, two quarters being moderately preserved and the last quarter being well-preserved. The large majority of artefacts of LB38 are poorly preserved and show an intense surface gloss. Also, all artefacts from LB25 are poorly preserved and show an intense surface gloss including rounded edges/ridges on $80 \%$ of the artefacts (cf. Figure $2 \mathrm{a}$ and $2 \mathrm{~d}$ ). Also, patination is abundantly present in spite of a near absence of heat alteration, thereby attesting that at the exception of LB01, other processes than heat are responsible for the formation of patina at this site. Finally, the edges/ridges of the majority of the studied LB25 artefacts show intense damage (cf. Figure 2c).

The alterations, and in particular the overall presence of gloss, indicate that aeolian activity severely impacted the artefacts. Differences in preservation between the concentrations can be 
linked with their location within the Late Glacial dune landscape. The concentrations at the base of the dune (LB01, LB60 and LB57A), and in particular at the base of the northern slope (LB01, LB60), were not affected by aeolian activity as they were covered by aeolian sands during the Younger Dryas. Artefact concentrations located on the dune ridge (LB25, LB38) were heavily exposed to aeolian activity, notably sandblasting, as deflation during the Younger Dryas surfaced the tools. This explains the high frequency of tools with intense surface gloss, patination and rounding (cf. Figure 3). Moreover, strong winds transported the stone tools, causing microscarring on the edges and ridges on a high number of tools. As the large majority of artefacts from LB25 and LB38 show a combination of these traces, they were classified as poorly preserved. 

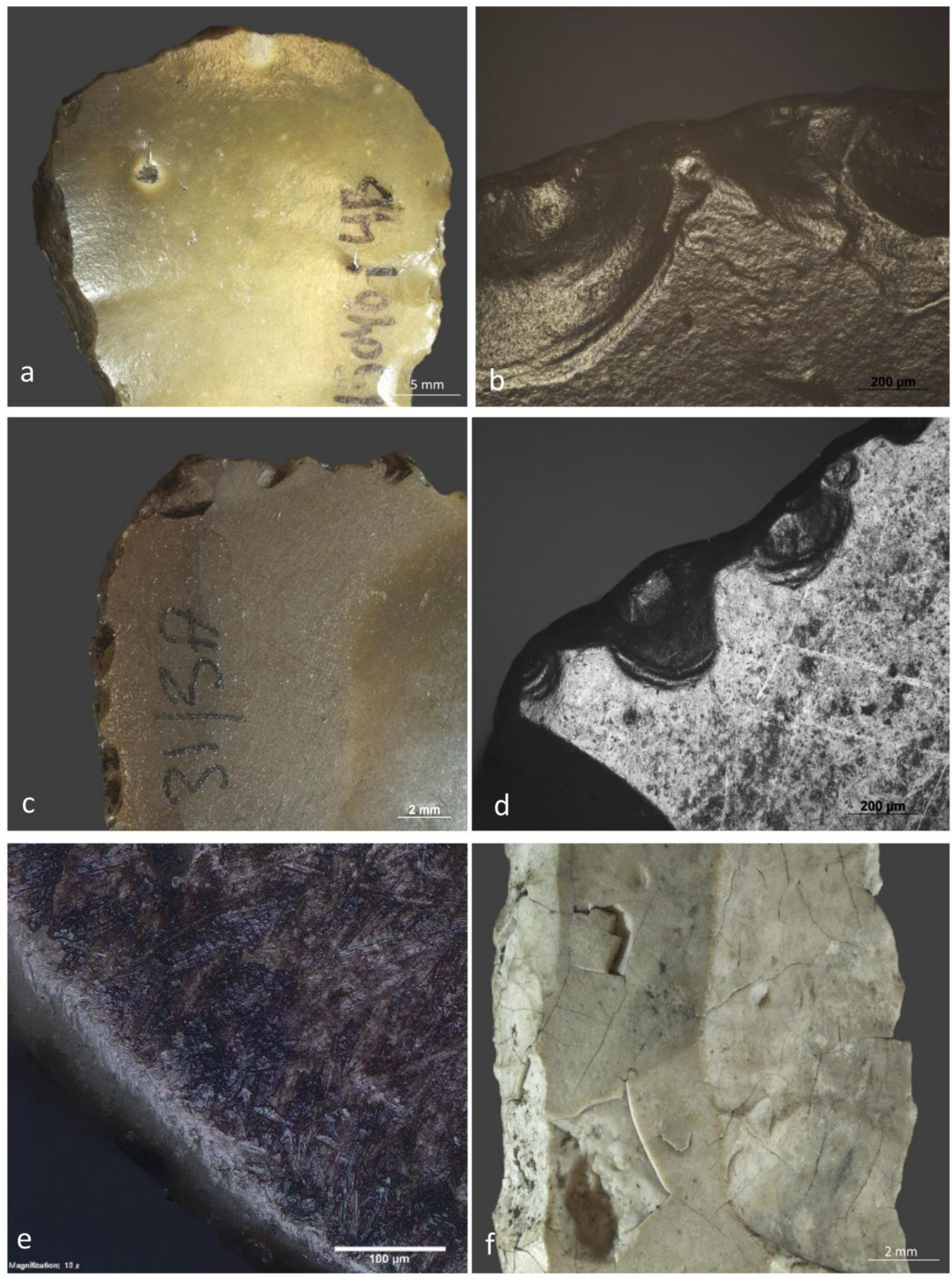

Figure 2 Macro and microscopic images illustrating the differential preservation as a result of taphonomic processes: a) distal part of scraper LB25_9 (6.3x) with heavy surface gloss and edge rounding; b) microscopic detail of the rounded edge and surface gloss of artefact LB38_1104 (100x); c) post-depositional edge scarring on the distal edges of piece LB25_54 (12.5x); d) microscopic detail of heavily developed surface gloss, striations and edge rounding on piece LB25_46 (100x); e) microscopic detail of the surface of 
the piece LB25_47 (100x) that is covered with a residual deposit and curved striations with diverse orientations; f) macroscopic detail of the heat-altered piece LB25_117 (16x) showing negatives, cracks, fissures and heavy patination.
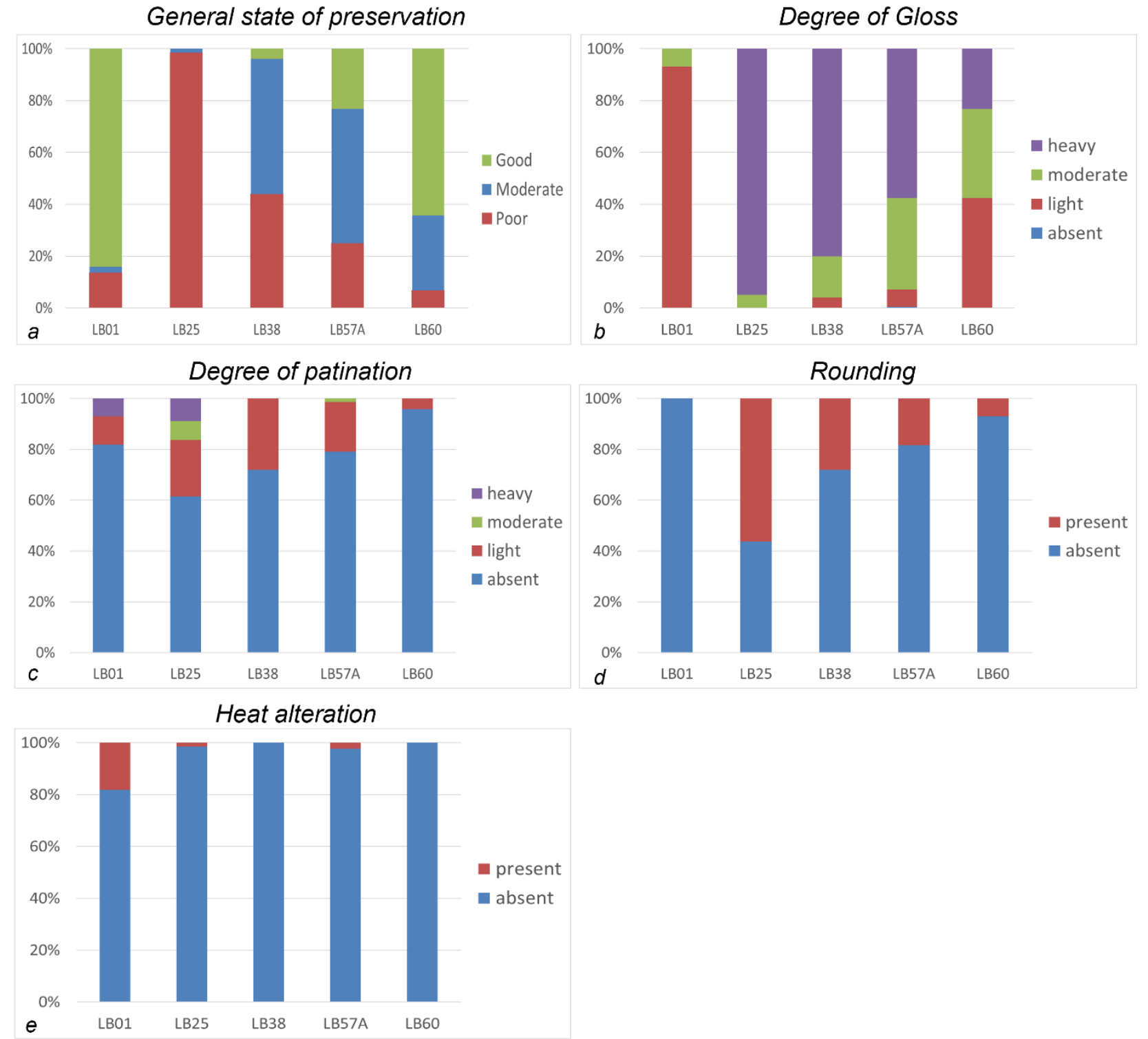

Figure 3 Summary of the recorded surface alterations including a) the general state of preservation; $b$ ) the degree of gloss; c) the degree of patination; d) the presence of edge rounding; e) the presence of heat alteration

Results show that aeolian activity has differentially affected the artefact concentrations, thereby creating a certain bias to the functional understanding of the site as use-wear can no longer be detected on the majority of LB38 and LB25 stone tools. Possible use-wear on these stone tools was most likely destroyed by taphonomic processes while this is less likely the case for stone tools of the three remaining concentrations. 


\subsection{Impact of excavation strategy}

The impact of the excavation strategy used at Lommel-Maatheide has been assessed through a detailed screening of 770 artefacts. During screening, the characteristics of metal traces, including their location and possible association with edge damage have been recorded. In order to assess the impact of sieving and excavation (e.g., contact with trowel or shovel) protocols, a more detailed recording of the wear caused by metal contact was made.

At Lommel-Maatheide, metal traces were present on 91 of the 770 screened lithics (12\%). Most of the traces consist of thin smears of metal residue, associated with fine striations (Figure 4), with no evidence of additional edge damage. Analysis of the residues with SEM-EDS reveals significant peaks of Iron (Fe), Chromium ( $\mathrm{Cr}$ ) and Nickel (Ni) and thus indicates contact with stainless steel (cf. Figure 5). The width (very fine) of both the striations and the residue smears are highly suggestive for contact with the stainless mesh screen used for sieving. Other metal traces consisting of wide linear features associated with edge damage were most likely caused by excavation equipment such as trowels or shovels, as these exert more pressure on the tool surface than contact with mesh screens.

To accurately map the density of the metal striations, each artefact was divided into twentysix zones. On the vast majority of the artefacts (79\%), metal traces were only present in a single zone, while a minority of artefacts showed metal traces in three or more zones (cf. Figure 6). Among the 91 artefacts with metal traces, 21 potentially used tools were affected by metal striations on their active edge but none of the traces truly hampered use-wear analysis.
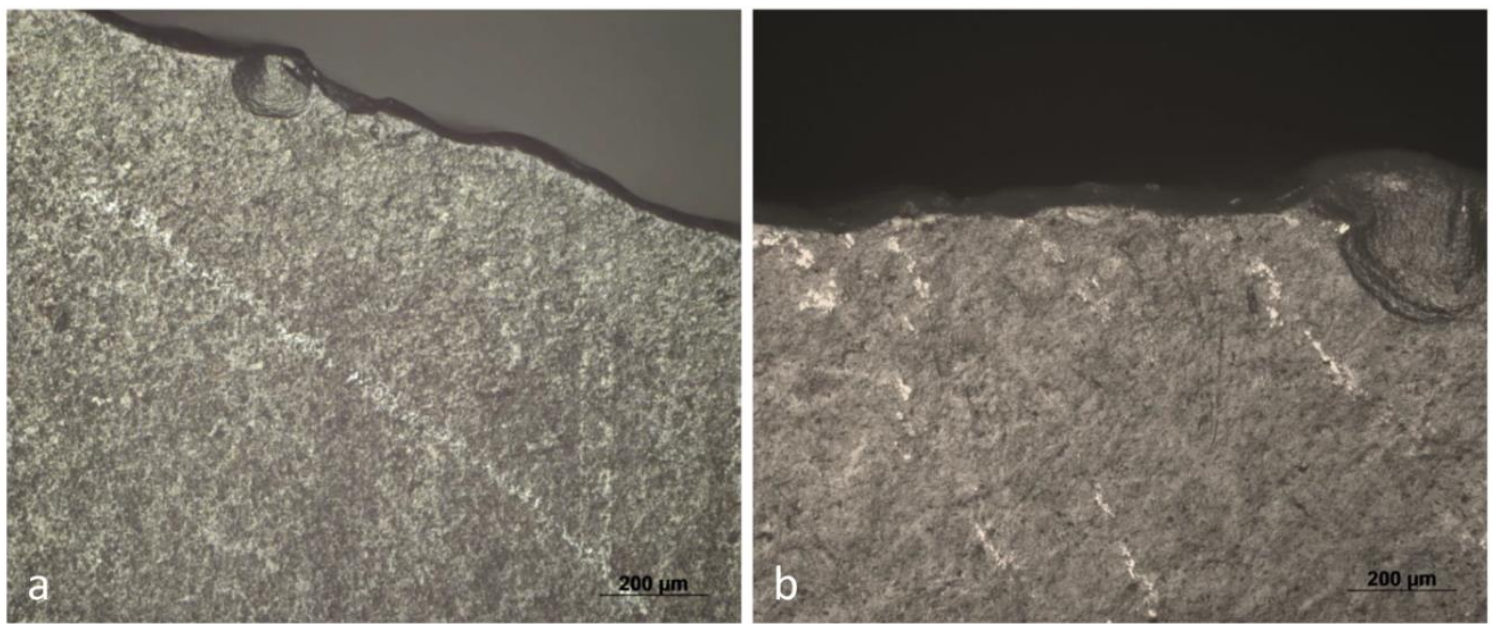

Figure 4 Microscopic details of metal traces, in the form of striations: a) on the ventral distal right edge of artefact LB25_7 (100x); b) on the ventral distal left edge of artefact LB25_24 (100x) 

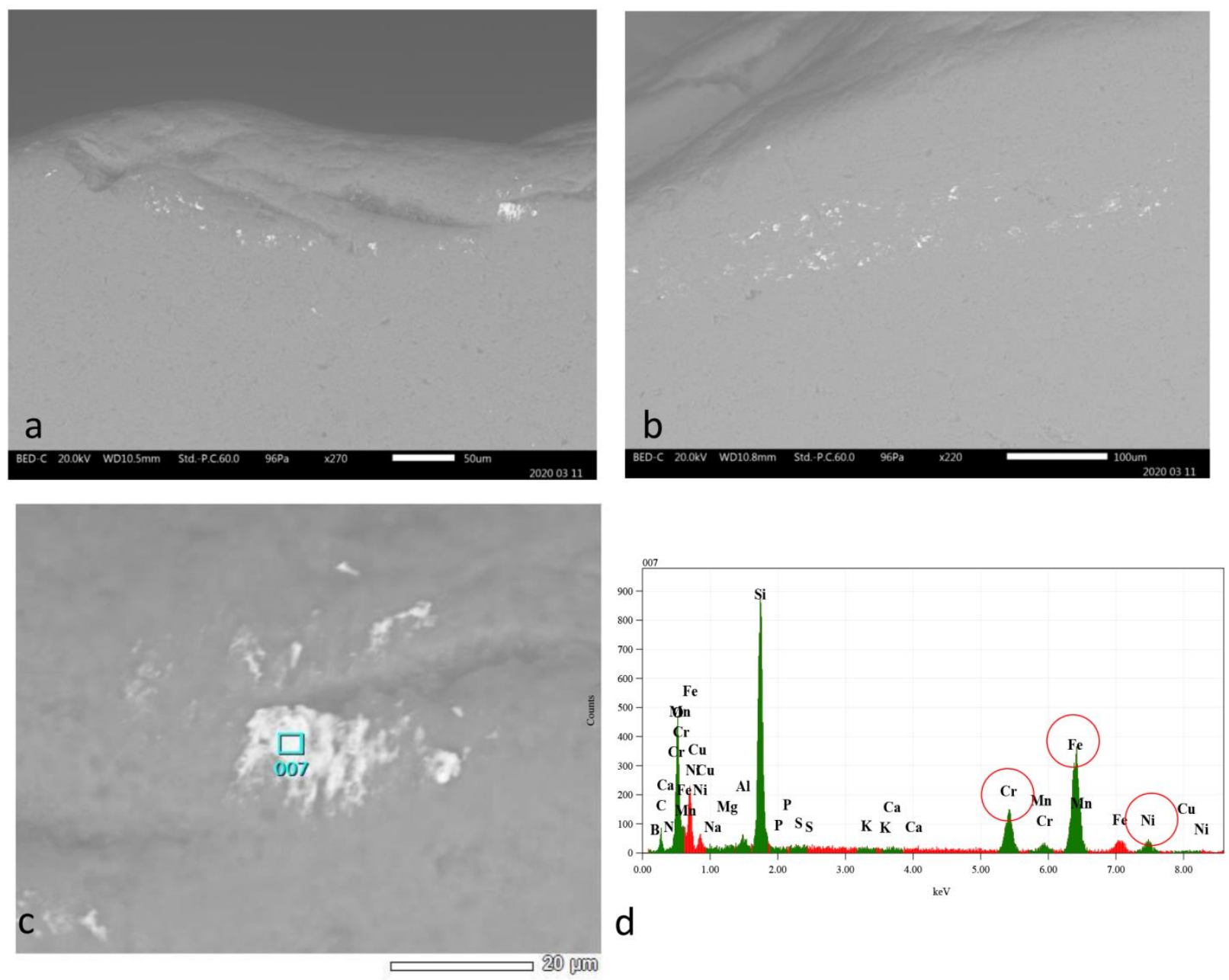

Figure 5 Metal traces: $a$ )+b) backscattered electron images of metal wear on the ventral distal surface of artefact LB25_24; c) detail of the smeared metal deposition with; d) the associated EDS mapping showing that the residue is composed of significant peaks of Iron (Fe), Chroom (Cr) and Nikkel (Ni) 


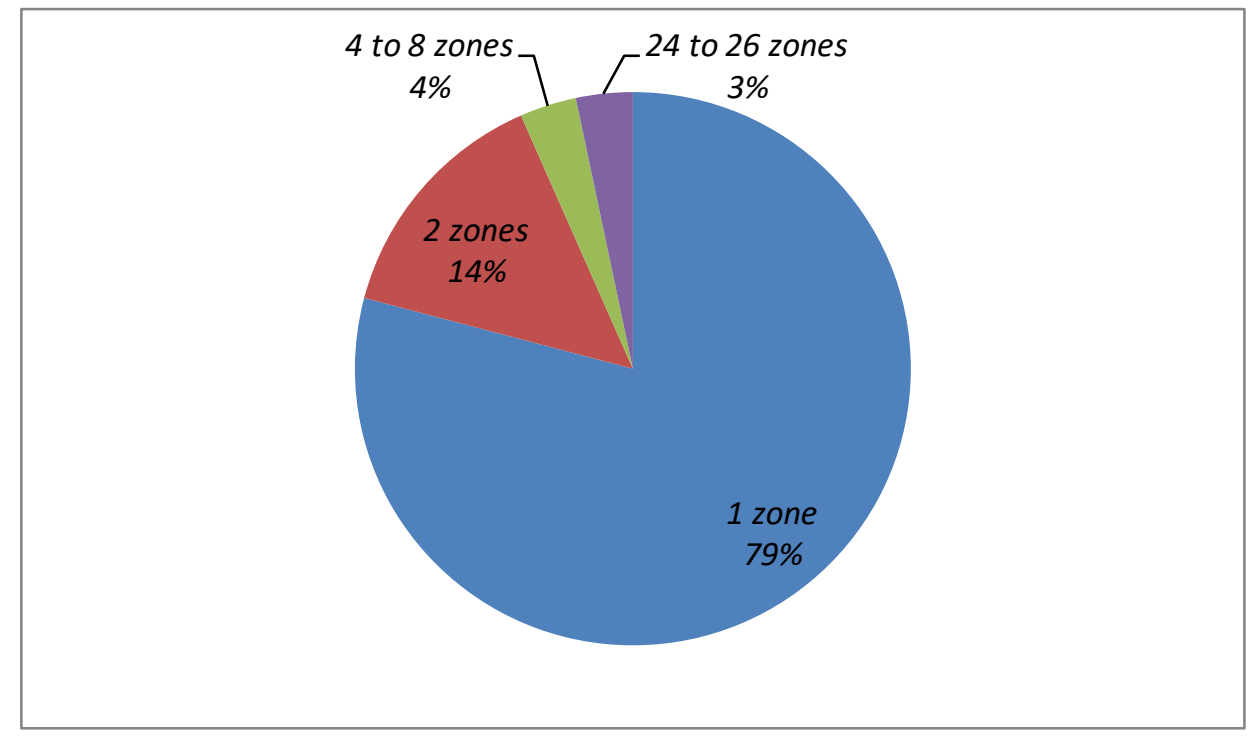

Figure 6 Artefacts with metal wear ( $N=91)$. Distribution of the metal traces and their frequency (according to the number of affected zones)

\subsection{Domestic tasks for each locus}

The integrated approach combining use-wear and residue analysis allowed obtaining highresolution data for all sufficiently preserved tools with distinctive traces. Given the importance of alterations, functionally diagnostic wear could not be observed on a large part of the selection. Out of a total of 56 analysed endscrapers, tool use could be identified on 11 of them, while 4 out of 6 analysed burins show evidence of use. Nevertheless, the functional results do provide a more dynamic view on the stone tools, their use and the broader activity range deployed at the site of Lommel-Maatheide. Here, the functional results are discussed per archaeological locus to assess if certain activities were linked with specific areas or occupations.

\subsubsection{LB01}

The screened artefacts $(\mathrm{N}=49)$ from locus LB01 mainly consisted of unretouched artefacts, as the entire assemblage proved to be composed of knapping waste with only ten burins as formal tools (De Bie et al. 2003). Refitting confirmed that these burins were found amongst their production waste and were thus produced locally (De Bie et al., 2003). The screening indicated that only these burins showed evidence of potential use and merited to be selected for detailed analysis. Burins proved to be primarily used on their distal extremity and along their facets in a shaving motion on hard animal materials (Table 5). Wear traces consisted of limited rounding on the tip and edges and a strongly developed polish associated with abundant striations oriented parallel to the edge of the burin facet (Figure 7). In case of two burins (LB01_6 and LB01_7), these wear traces could be attributed to soaked antler on the basis of an existing experimental 
reference (Figure 8). On two other burins (LB01_1 and LB01_4), traces proved similar, but due to the presence of a post-depositional gloss, interpretation is less certain.

\begin{tabular}{llllll}
\hline Tool Id & $\begin{array}{l}\text { Tool } \\
\text { category }\end{array}$ & Fragmentation & $\begin{array}{l}\text { Post-depositional } \\
\text { damage }\end{array}$ & Interpretation tool use & $\begin{array}{l}\text { Interpretation } \\
\text { Hafting }\end{array}$ \\
\hline LB01_1 & complete & moderate gloss & possibly used (1) & unidentified (0) \\
LB01_7 & complete & moderate gloss & shaving soaked antler (2) & unidentified (0) \\
LB01_2 & burin & complete & moderate gloss & unidentied (0) & hafted (2) \\
LB01_4 & complete & light gloss & used on hard animal material & hafted (2) \\
LB01_6 & complete & heavy gloss & used on soaked antler (2) & unidentified (0) \\
\hline
\end{tabular}

Table 5 Overview of the five burins from locus LBO1 with use-wear evidence (level of certainty related to the interpretation: uncertain (0) poor certainty (1); moderate certainty (2); high certainty (3); certain (4))

At least two burins (LB01_2 and LB01_4) proved to have been used hafted. Hafting wear includes lateral scarring, friction or polish spots (Figure 7) and edge crushing. The abrupt appearance of scarring on the mesial lateral edge and the bright spot associated with rounding on the prominent part of the mesial dorsal ridge were interpreted as hafting wear and suggest that the lateral edges and dorsal ridge were in contact with a harder haft material (cf. Rots, 2008). However, traces were not well-developed and should thus be interpreted with caution. 

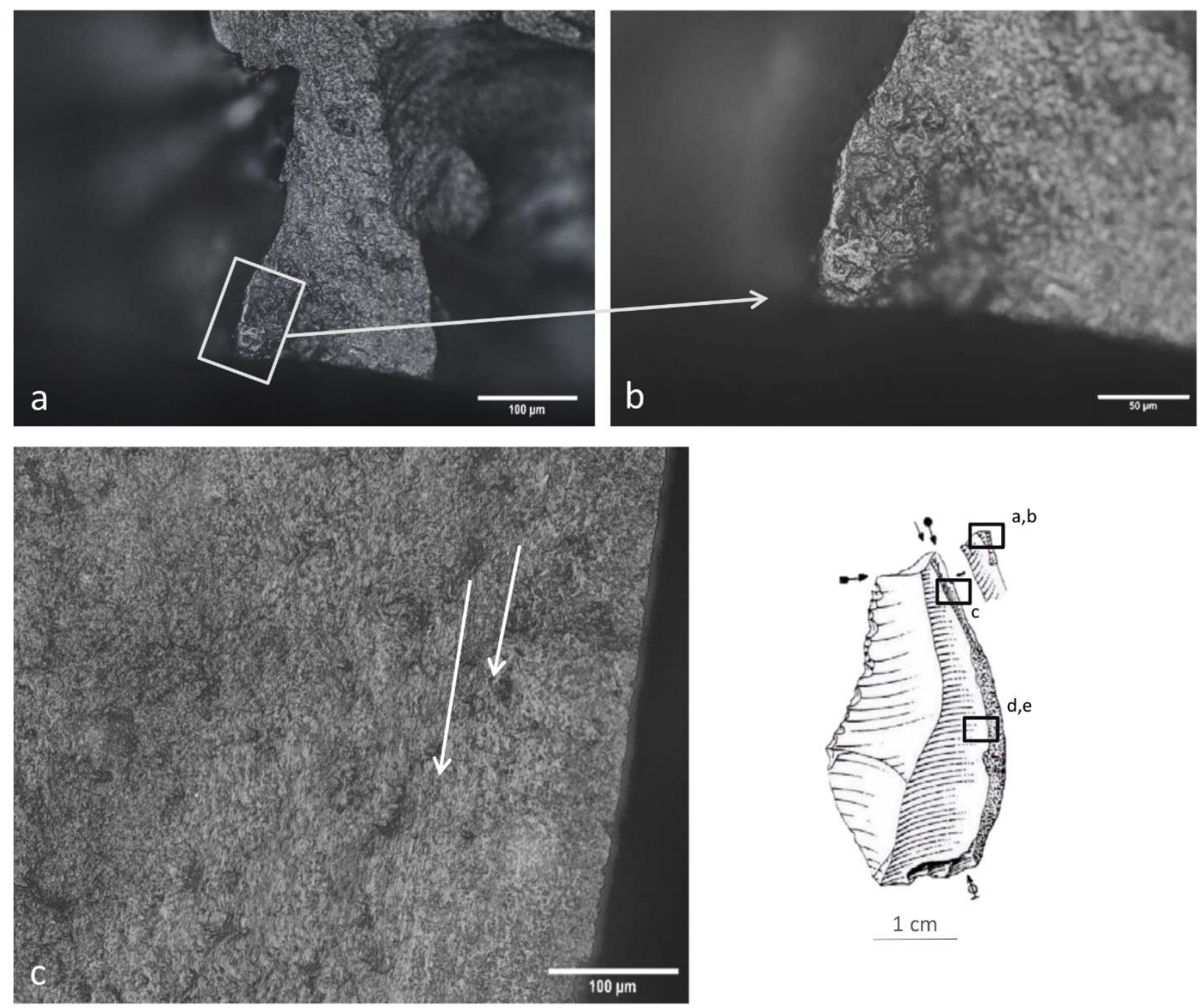

$1 \mathrm{~cm}$
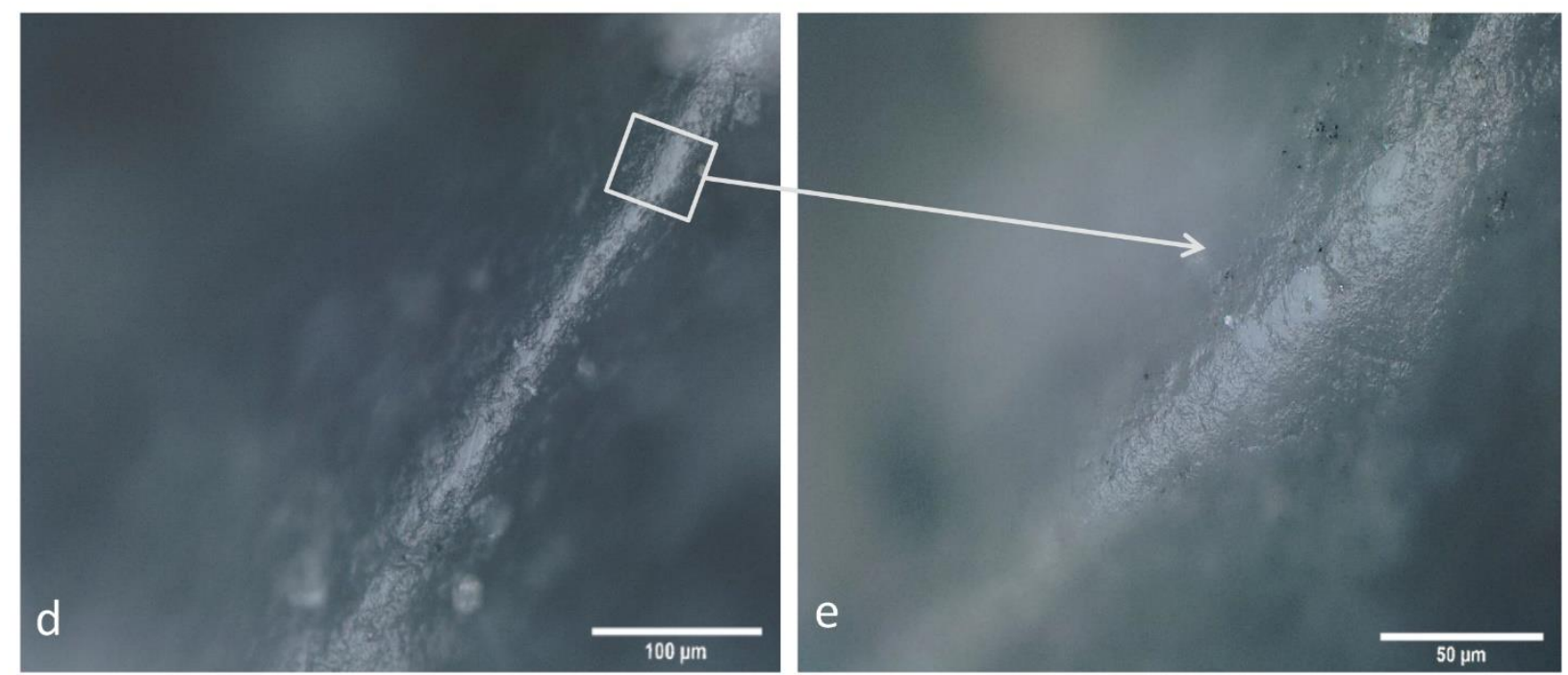

Figure 7 Burin LB01_4 interpreted as having been used on hard animal material; with a)+b) slight edge and tip rounding associated with a bright polish restricted to the prominent zone of the tip (100x and 200x); c) detail of the burin-facet with bright use polish, 
multiple use-related striations oriented parallel to the edge (100x); d)+e) details of the bright spot observed on the protruding part of the dorsal mesial ridge of the burin (100x and 200x) interpreted as a potential indication for hafting.
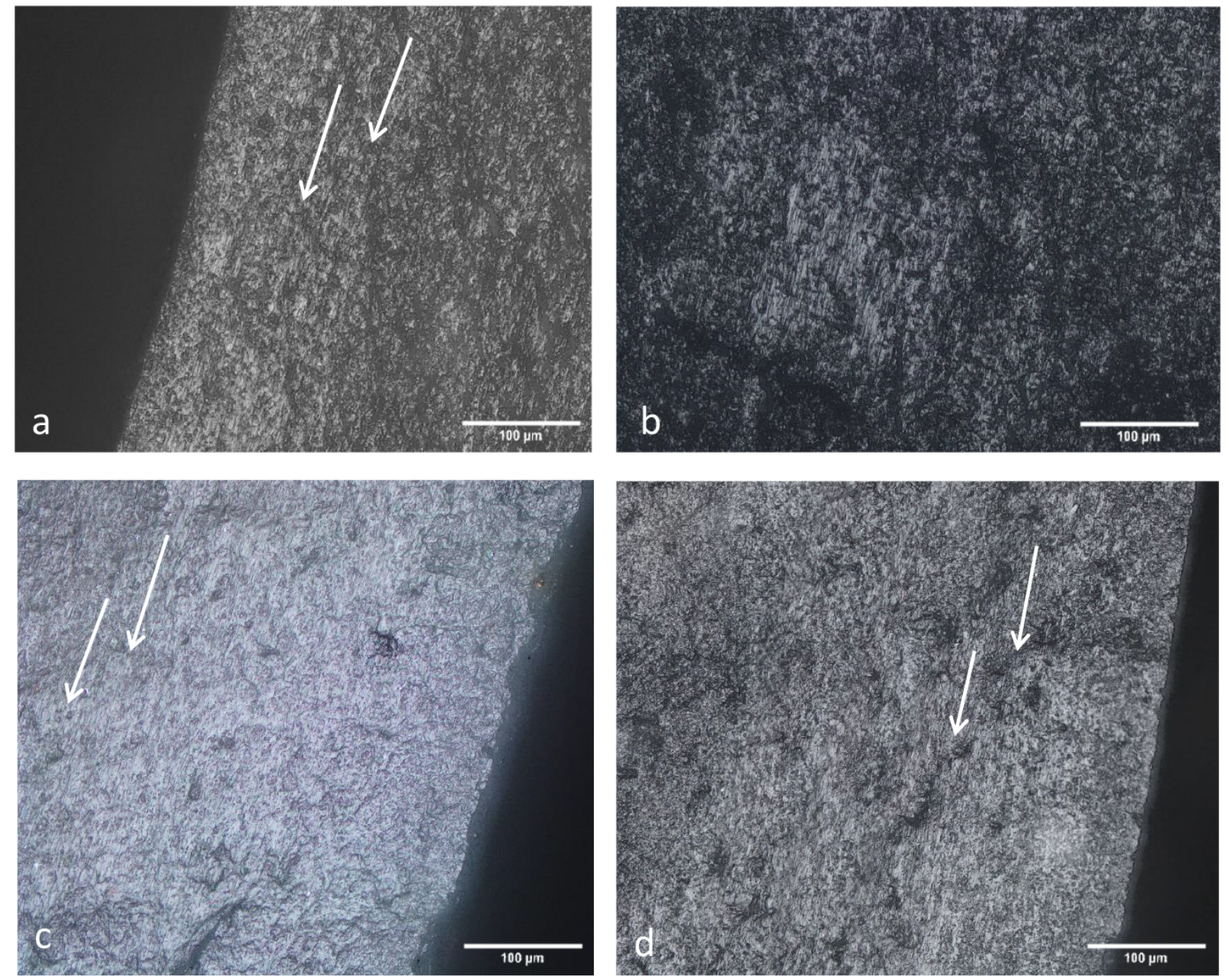

Figure $8 a$ )+b) Experimental burin (EXP16_2) (cf. Rots, 2010) used on soaked antler with microscopic details of the bright and greasy polish associated with multiple striations oriented parallel to the facet edge (100x and 200x); c) microscopic detail of a slightly pitted, smooth polish associated with multiple striations observed on the archaeological burin facet LB01_7 (100x); d) microscopic detail of similar wear features observed on the archaeological burin facet LB01_4 (100x).

\subsubsection{LB25}

LB25 represents the largest concentration of the site, but the artefacts were heavily affected by aeolian surface alterations. In total, 389 artefacts were screened ( $N=135$ domestic tools \& N=254 armatures) for wear damage and 42 domestic tools showed probable evidence of use and were thus selected for more detailed analysis.

Due to an overall poor preservation state, only 6 of 42 artefacts showed wear traces that permitted a reliable confirmation of use. For the other tools, the combination of severe surface alterations with poor development of wear traces lead to a relatively small number of identified used tools. 
Use-wear traces were better developed on five endscrapers and on one burin (cf. Table 6). The burin (LB25_87) seemed to be used with its distal part in a longitudinal motion on hard animal material. The distal part, especially the distal right ventral edge showed a light rounding, friction spots and a delimited smooth-pitted polish oriented parallel to the edge. The scrapers were used in transversal motions on soft animal materials, most likely on hides. On two scrapers, wear traces composed of a rough and dull polish with associated edge rounding and perpendicularly oriented straight striations on the ventral surface were attributed to dry hide scraping. For the three remaining scrapers, the identification of the worked material was more difficult due to an overlying taphonomic surface gloss. One of the scrapers (LB 25_53) showed light edge rounding and a greasy and bright polish on its distal ventral edge, which possibly resulted from fresh hide scraping. Wear traces observed on the distal ventral surface were associated with a smeared residual deposit that proved to be organic in nature and potentially related to the worked material (cf. Figure 9).

Possible evidence of hafting was observed on two endscrapers (LB25_4 \& LB25_53) but consisted mainly of macroscopic wear features that were interpreted with a poor level of confidence only. Given the post-depositional surface alteration, no additional microscopic wear could be identified. In addition to the macroscopic wear features, the morphological characteristics indicated that the breakage of one of the endscrapers occurred possibly accidentally during resharpening, while the other small endscraper seemed to be used and resharpened up to the point of exhaustion.

\begin{tabular}{|c|c|c|c|c|c|}
\hline Tool Id & $\begin{array}{l}\text { Tool } \\
\text { category }\end{array}$ & $\begin{array}{c}\text { Frag- } \\
\text { mentation }\end{array}$ & Post-depositional damage & Interpretation tool use & $\begin{array}{l}\text { Interpretation } \\
\text { Hafting }\end{array}$ \\
\hline LB25_4 & & complete & $\begin{array}{l}\text { light patina, heavy gloss, edge } \\
\text { rounding, abrasion on dorsal } \\
\text { ridge }\end{array}$ & possibly used (1) & $\begin{array}{l}\text { possibly hafted } \\
\text { (1) }\end{array}$ \\
\hline LB25_15 & & complete & heavy gloss & possibly used (1) & unidentified (0) \\
\hline LB25_17 & endscraper & distal part & moderate gloss & possibly used (1) & unidentified (0) \\
\hline LB25_53 & & distal part & $\begin{array}{l}\text { light patina, heavy gloss, edge } \\
\text { and ridge rounding, metal wear }\end{array}$ & scraping soft animal (4) & $\begin{array}{l}\text { possibly hafted } \\
\text { (1) }\end{array}$ \\
\hline LB25_57 & & complete & heavy gloss & scraping soft animal (4) & unidentified (0) \\
\hline LB25_87 & burin & complete & $\begin{array}{l}\text { light patina, heavy gloss, edge } \& \\
\text { ridge rounding }\end{array}$ & $\begin{array}{l}\text { used on hard animal } \\
\text { material (2) }\end{array}$ & hafted (2) \\
\hline
\end{tabular}

Table 6 Overview of the six tools from locus LB25 with use-wear evidence (scale of certainty related to the interpretation: uncertain (0) poor certainty (1); moderate certainty (2); high certainty (3); certain (4)) 

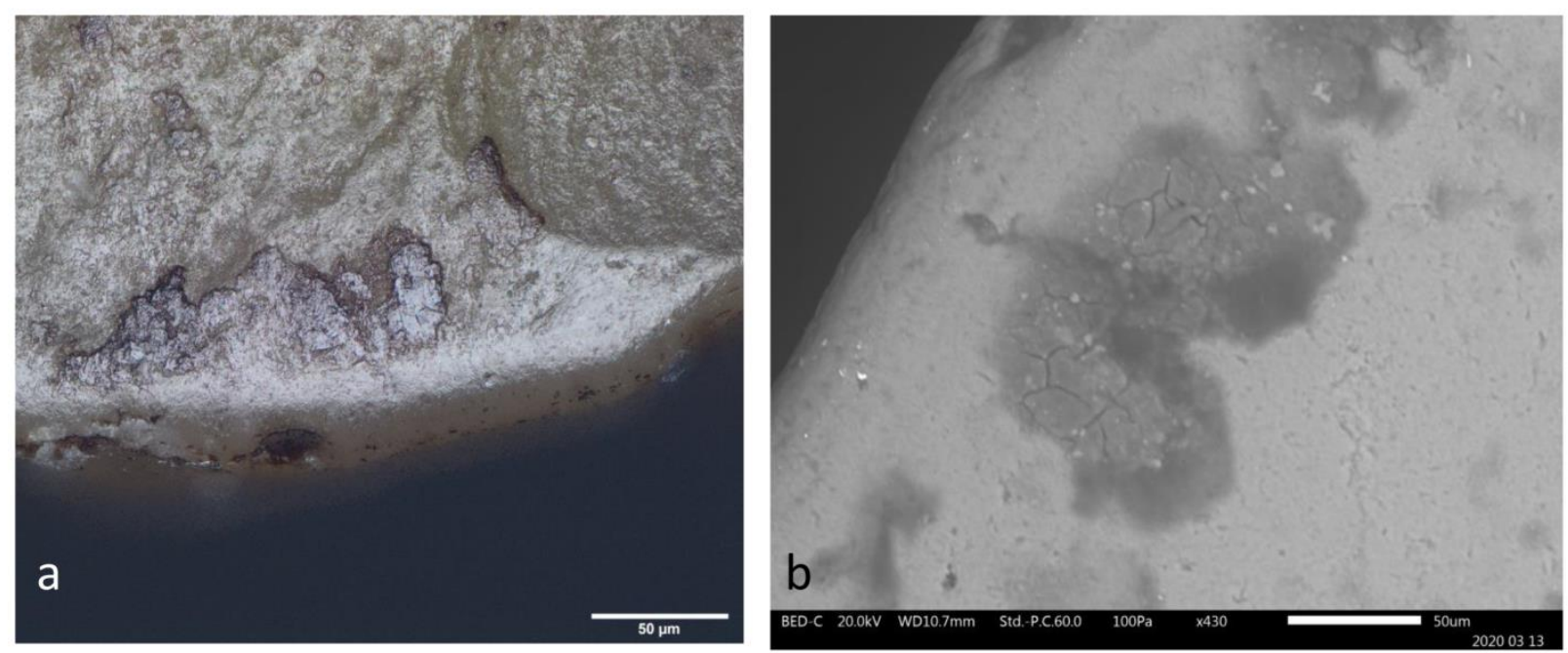

Figure 9 Endscraper LB25_53 interpreted as being used on soft animal material: a) microscopic detail of well-pronounced rounding from use on the distal ventral right edge of the scraper, with the additional presence of a black smeared organic residual deposition (200x); b) backscattered electron image showing a detail of the rounded distal ventral edge of the tool with adhering organic residual depositions (430x).

\subsubsection{LB38}

Only two out of 23 screened artefacts showed potential evidence of use, which is most likely due to the presence of severe alterations on the majority of artefacts from LB38, in particular a combination of a heavy gloss and light patina. The subsequent analysis on these two artefacts did not reveal any diagnostic use traces on these artefacts.

\subsubsection{LB57A}

On a macroscopic scale, $10 \%(N=23)$ of the screened artefacts $(N=224)$ show possible userelated traces. This was further confirmed during the microscopic analysis for 7 artefacts in total (cf. Table 7). Detailed examination showed that primarily endscrapers were used, more specifically in transversal use motions. The visibility of use-wear traces was hindered significantly by surface alterations, but also resharpening removed part of the wear traces, while the poor development of some other wear traces was probably the result of relatively short use durations. 


\begin{tabular}{|c|c|c|c|c|c|}
\hline Tool Id & $\begin{array}{l}\text { Tool } \\
\text { category }\end{array}$ & $\begin{array}{l}\text { Fragment } \\
\text { ation }\end{array}$ & Post-depositional damage & Interpretation tool use & $\begin{array}{l}\text { Interpretation } \\
\text { Hafting }\end{array}$ \\
\hline LB57A_71 & & complete & $\begin{array}{l}\text { moderate gloss, metal } \\
\text { wear }\end{array}$ & used (1) & unidentified (0) \\
\hline LB57A_19 & & distal & $\begin{array}{l}\text { moderate gloss, metal } \\
\text { wear }\end{array}$ & used (1) & unidentified (0) \\
\hline LB57A_30 & & complete & heavy gloss, edge rounding & used (0) & unidentified $(0)$ \\
\hline LB57A_64 & endscraper & complete & $\begin{array}{l}\text { moderate gloss, edge } \\
\text { rounding, }\end{array}$ & used (1) & unidentified $(0)$ \\
\hline LB57A_63 & & complete & moderate gloss & used on vegetal material (4) & unidentified (0) \\
\hline LB57A_1 & & complete & light gloss & $\begin{array}{l}\text { scraping vegetal material } \\
\text { (4) }\end{array}$ & possibly hafted (1) \\
\hline LB57A_76 & & complete & light gloss, metal wear & used (1) & unidentified $(0)$ \\
\hline
\end{tabular}

Table 7 Overview of the seven endscrapers from locus LB57a with use-wear evidence (Scale of certainty related to the interpretation: uncertain (0) poor certainty (1); moderate certainty (2); high certainty (3); certain (4)).

The material worked could only be identified on two tools and proved to concern vegetal materials. Traces consisted of abrasive striations with a perpendicular or slightly oblique orientation to the working edge, associated with a pronounced edge rounding and a bright/reflective, smooth polish, with no edge scarring (cf. Figure 10). The wear pattern proved similar to what has been interpreted previously as "Polish 23" (e.g., (Caspar et al. 2005; Van Gijn 1990). Polish 23 is known to have two components, each on one of the faces of the same edge (Caspar et al. 2005). The bright polish component has all features characteristic for a plant polish (rich in silica) (Jensen, 1994), while the other component consists of extensive edge rounding in association with multiple striations and its cause is not yet entirely clear, but may be the result of contact with a relatively soft, though abrasive material, for instance flax fiber processing, as experimentally documented (Beugnier and Crombé, 2007; Van Gijn and Mazzucco, 2013).

At the exception of one tool, traces from hafting or hand-held use were almost absent. Only the friction wear on the ventral lateral right mesial edge of scraper LB57A_1 appears to be due to hafting. Hafting is further suggested by the abrupt termination of the bright use polish in the mesial part that appears to correspond to the boundary of the handle. 

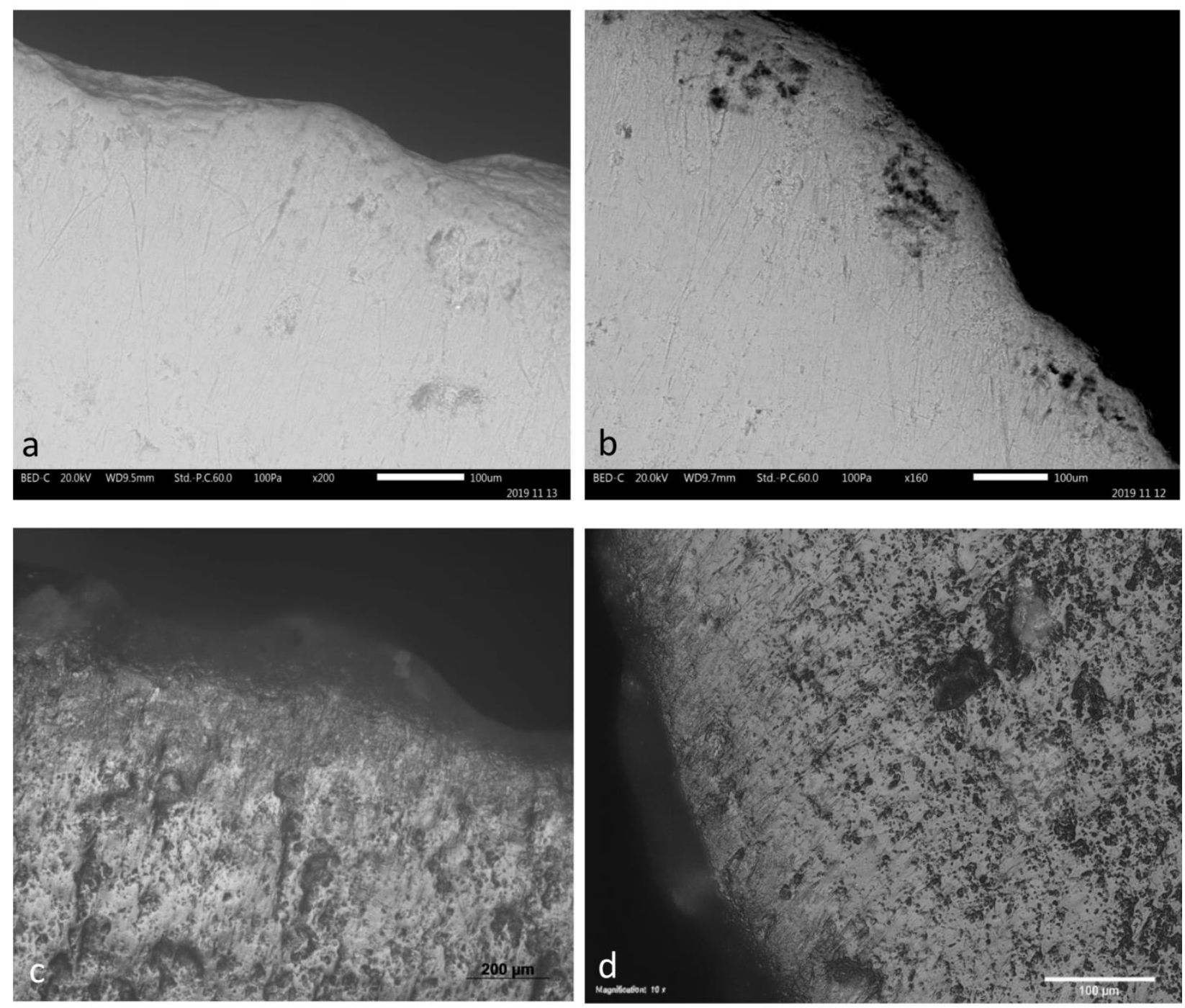

Figure 10 Details of wear traces and residues observed on the distal edge of scraper LB57A_1 interpreted as having been used on a soft material, most likely a vegetal material rich in silica: a)+b) backscattered electron images showing the rounded distal ventral edge of the tool, with striations indicating the transversal motion and the adhering organic residual depositions; c) $+d)$ microscopic detail of the distal rounded edge, with a rough and bright polish and numerous striations (100x).

\subsubsection{LB60}

A total of 73 artefacts was screened, but no use-wear was observed, despite the good preservation state of the material. The reason is probably that no formal tools were selected for screening though 21 tools are present for this locus. An extension of the selection is thus required in order to properly evaluate tool use for this locus. 


\subsection{Hunting tasks for each locus}

\subsubsection{Identification of projectile elements}

\subsubsection{LB25}

Out of the original selection (254 curved backed points), 74 pieces presented a sufficient preservation state to proceed to a more detailed analysis and an examination of projectile evidence. Attention was devoted to the occurrence of fractures and damage mainly with attention to the association between the traces and the trace patterning over the tool (Rots and Plisson 2014). An evaluation of the presence of MLITs (i.e., microscopic linear impact trace (Moss 1983) was not possible given the presence of a strongly developed post-depositional gloss (see section taphonomy) (cf. Figure 2), in spite of their high relevance in projectile identifications (Rots and Plisson 2014). A total of 27 pieces (27/74 or 44\%) presents a combination of damage features (bending breaks, oriented lateral scarring and secondary damages) that permits to identify them as definite projectile elements (cf. Figure 11, Figure 12 \& Figure 13) (Coppe and Rots 2017). The main fracture categories registered for pieces identified as projectile element and pieces which do not present a convincing fracture pattern are presented in Table 8 . The details of the attributes recorded for each fracture on the projectile elements that could be identified with certainty $(\mathrm{N}=27)$ are presented in Table 9.

\begin{tabular}{lcccc}
\hline & \multicolumn{2}{c}{ Pieces identified as projectile elements } & \multicolumn{2}{c}{ Pieces not identified as projectile elements } \\
\hline & Number of pieces & Number of fractures & Number of pieces & Number of fractures \\
& $(\mathrm{N}=27)$ & $(154)$ & $(\mathrm{N}=47)$ & $(89)$ \\
Bending breaks & $25(92 \%)$ & $35(22 \%)$ & $30(64 \%)$ & $37(42 \%)$ \\
Secondary damage & $19(70 \%)$ & $35(22 \%)$ & $0(0 \%)$ & $0(0 \%)$ \\
Perpendicular lateral & $8(29 \%)$ & $8(5 \%)$ & $19(40 \%)$ & $33(37 \%)$ \\
scarring & & & $13(28 \%)$ & $19(21 \%)$ \\
Oblique lateral scarring & $24(89 \%)$ & $76(51 \%)$ & 19 & \\
\hline
\end{tabular}

Table 8 Overview of the representation of the four fractures categories in the sample of indentified projectile in comparaison with the rest of the curved backed point sample from LB25 locus. 


\begin{tabular}{|c|c|c|c|c|}
\hline & & & \multicolumn{2}{|c|}{$\begin{array}{c}\text { Pieces identified as projectile } \\
\text { elements }(\mathrm{N}=27)\end{array}$} \\
\hline & & & $N$ fractures & N pieces \\
\hline \multirow[t]{6}{*}{ Bending Breaks } & \multirow[t]{4}{*}{ Termination morphology } & Snap & 7 & 6 \\
\hline & & Abrupt (step or hinge) & 20 & 17 \\
\hline & & Feather & 3 & 3 \\
\hline & & Indeterminate & 5 & 5 \\
\hline & \multirow[t]{2}{*}{ Fissure of termination } & Yes & 8 & 8 \\
\hline & & No & 25 & 18 \\
\hline \multicolumn{3}{|l|}{ Total Bending breaks } & 35 & 24 \\
\hline \multirow[t]{11}{*}{ Secondary damage } & \multirow[t]{2}{*}{ Fracture composition } & Simple & 17 & 12 \\
\hline & & Multiple & 18 & 12 \\
\hline & \multirow[t]{2}{*}{ Initiation conservation } & Absent & 15 & 9 \\
\hline & & Present & 20 & 14 \\
\hline & \multirow[t]{3}{*}{ Initiation morphology } & Cone & 22 & 15 \\
\hline & & Bending & 2 & 2 \\
\hline & & Mixed & 5 & 4 \\
\hline & \multirow[t]{2}{*}{ Fissure of termination } & Yes & 16 & 11 \\
\hline & & No & 19 & 13 \\
\hline & \multirow[t]{2}{*}{ Location of termination } & Same as bending break & 16 & 13 \\
\hline & & Opposite to bending break & 19 & 14 \\
\hline \multicolumn{3}{|c|}{ Total Secondary damage } & 35 & 18 \\
\hline \multirow[t]{12}{*}{ Lateral scars } & \multirow[t]{2}{*}{ Fracture composition } & Simple & 39 & 18 \\
\hline & & Multiple & 45 & 17 \\
\hline & \multirow[t]{2}{*}{ Initiation } & Absent & 23 & 12 \\
\hline & & Present & 63 & 23 \\
\hline & \multirow[t]{3}{*}{ Initiation morphology } & Cone & 13 & 7 \\
\hline & & Bending & 55 & 22 \\
\hline & & Intermediate & 13 & 9 \\
\hline & \multirow[t]{2}{*}{ Fissure of termination } & Yes & 21 & 9 \\
\hline & & No & 61 & 21 \\
\hline & \multirow{3}{*}{$\begin{array}{l}\text { General direction with } \\
\text { regard to the axis of the } \\
\text { piece }\end{array}$} & Oblique & 59 & 22 \\
\hline & & Variable & 17 & 13 \\
\hline & & Perpendicular & 8 & 8 \\
\hline \multicolumn{3}{|l|}{ Total Lateral scars } & 84 & 24 \\
\hline \multicolumn{3}{|l|}{ Total } & 154 & 27 \\
\hline
\end{tabular}

Table 9 Details of the representation of the different fractures attributes inside the sample of identified projectile from LB25 locus. 


$$
E
$$




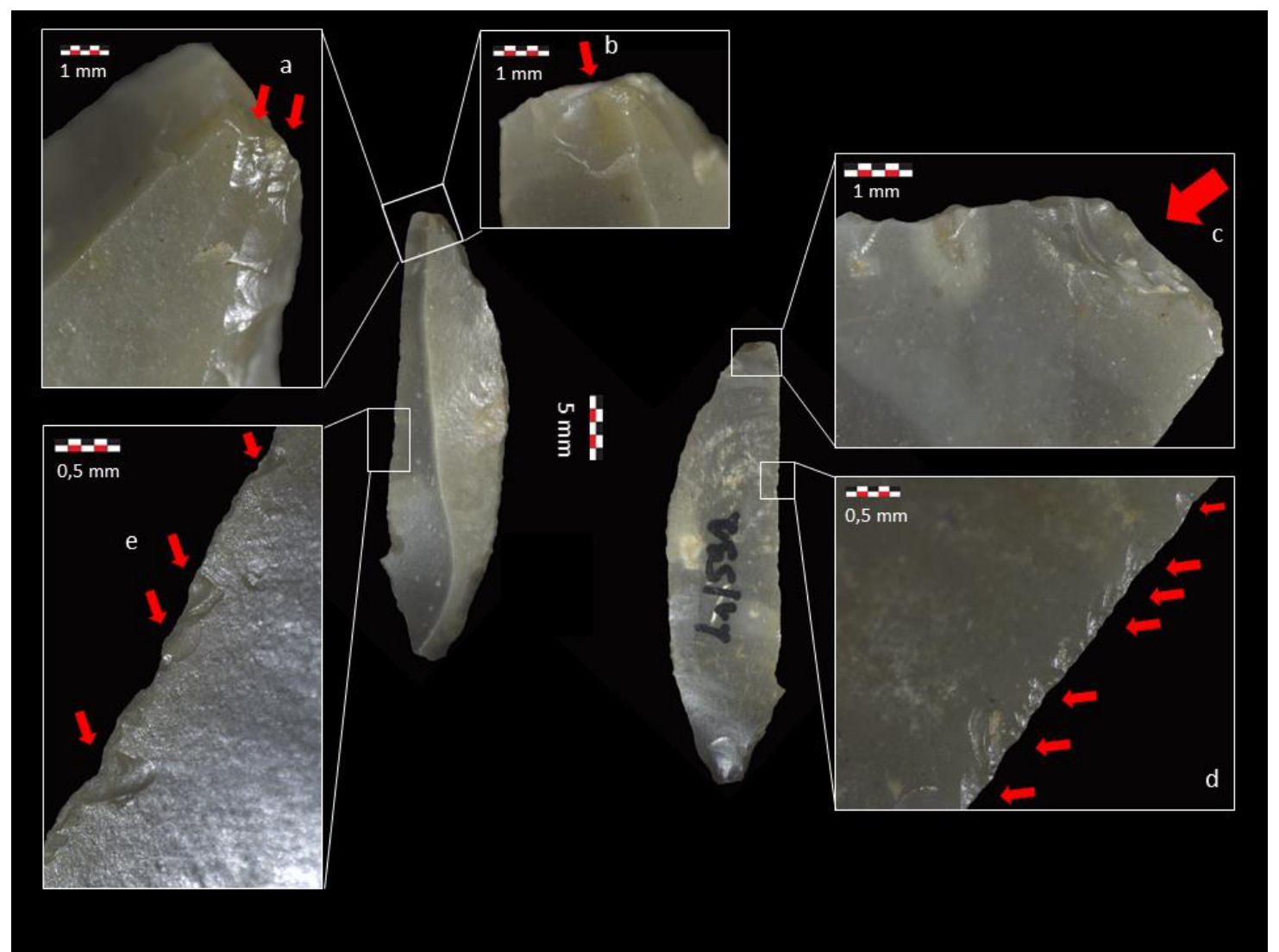

Figure 12 Macroscopic details of the impact damage present on the curved backed piece L1591 identified as a projectile. The piece presents: $a)+b)+c$ ) a combination of bending breaks, secondary damage and e)+d) oriented lateral scarring.

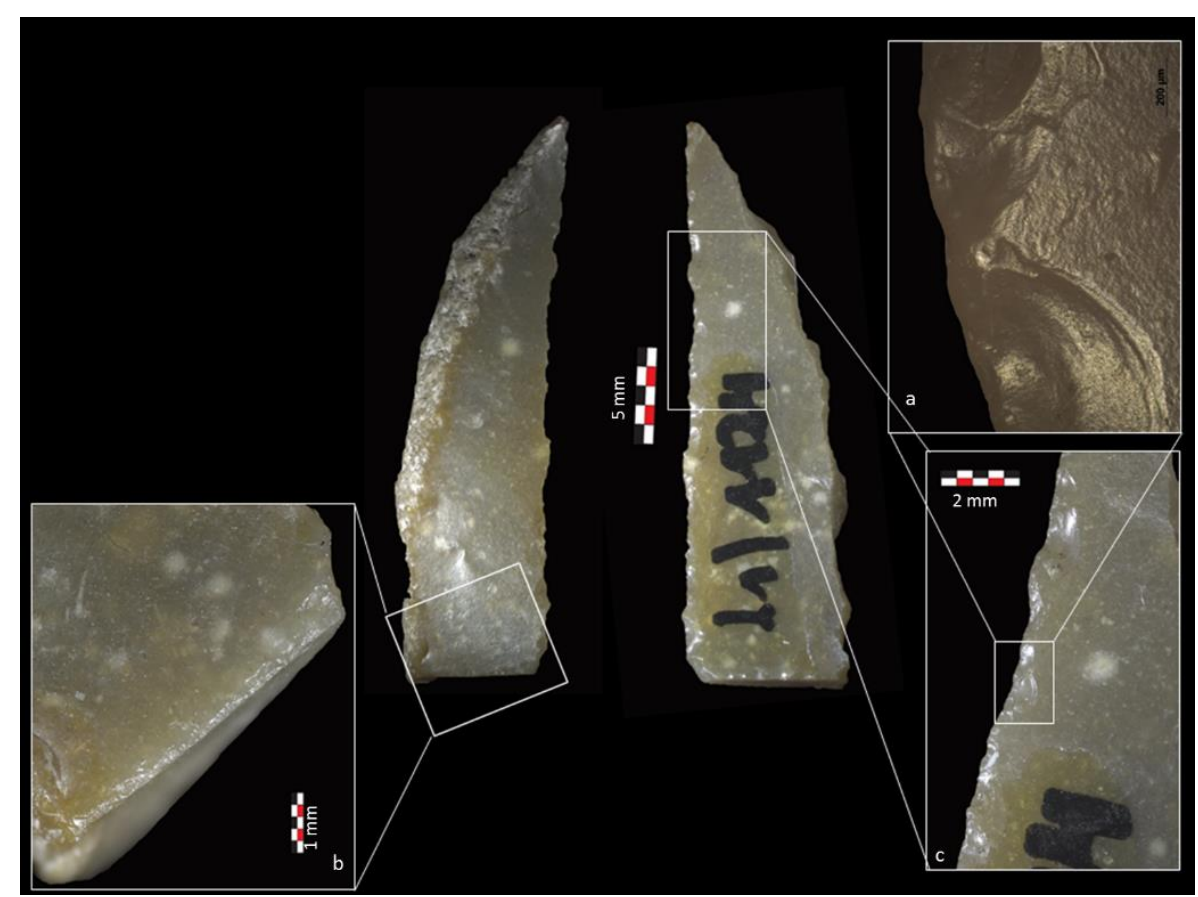

Figure 13 Macro and microscopic details of surface alterations caused by aeolian erosion on the curved backed point L11124 which hindered the impact fracture analysis: a) microscopic detail of the edge scarring (see picture c)) with visible edge rounding and surface gloss; b) proximal edge scarring; c) lateral edge scarring. 


\subsubsection{LB57A}

Out of the complete sample of 12 curved backed points, 9 pieces presented a sufficient state of preservation to proceed to a detailed analysis of the fractures but preservation was insufficient to evaluate the presence of MLITs (Moss 1983). This analysis showed that 5 pieces present a combination of damage features (bending breaks, oriented lateral scarring and secondary damage) that permits to identify them as definite projectile elements (Coppe and Rots 2017). The details of the main fracture categories observed on pieces identified as projectile elements and on those that do not present a convincing fracture pattern are presented in Table 10. The details of the fracture attributes for the pieces identified as projectile elements are presented in Table 11.

\begin{tabular}{lcccc}
\hline & \multicolumn{2}{c}{ Pieces identified as projectile elements } & \multicolumn{2}{c}{ Pieces not identified as projectile elements } \\
\hline & Number of pieces & Number of fractures & Number of pieces & Number of fractures \\
& $(\mathrm{N}=5)$ & $(21)$ & $(\mathrm{N}=4)$ & 1 \\
Bending breaks & 5 & 7 & 1 & 0 \\
Secondary damage & 4 & 7 & 0 & 7 \\
$\begin{array}{l}\text { Perpendicular lateral } \\
\text { scarring }\end{array}$ & 0 & 0 & 3 & 7 \\
Oblique lateral scarring & 4 & 7 & 2 & 7 \\
\hline Table 10 Overview of the occurrence of the four fractures categories within the curved backed point sample of locus LB57A.
\end{tabular}




\begin{tabular}{|c|c|c|c|c|}
\hline & & & \multicolumn{2}{|c|}{$\begin{array}{c}\text { Pieces identified as } \\
\text { projectile elements }(\mathrm{N}=5)\end{array}$} \\
\hline & & & $N$ fractures & $N$ pieces \\
\hline \multirow[t]{6}{*}{ Bending Breaks } & \multirow[t]{4}{*}{ Termination morphology } & Snap & 1 & 1 \\
\hline & & Abrupt (step or hinge) & 4 & 4 \\
\hline & & Feather & 1 & 1 \\
\hline & & Indeterminate & 1 & 1 \\
\hline & \multirow[t]{2}{*}{ Fissure of termination } & Yes & 1 & 1 \\
\hline & & No & 4 & 4 \\
\hline \multicolumn{3}{|l|}{ Total Bending breaks } & 7 & 6 \\
\hline \multirow[t]{11}{*}{ Secondary damage } & \multirow[t]{2}{*}{ Fracture composition } & Simple & 2 & 2 \\
\hline & & Multiple & 5 & 4 \\
\hline & \multirow[t]{2}{*}{ Initiation conservation } & Absent & 3 & 3 \\
\hline & & Present & 4 & 4 \\
\hline & \multirow[t]{3}{*}{ Initiation morphology } & Cone & 3 & 4 \\
\hline & & Bending & 1 & 2 \\
\hline & & Mixed & 0 & 0 \\
\hline & \multirow[t]{2}{*}{ Fissure of termination } & Yes & 1 & 1 \\
\hline & & No & 6 & 4 \\
\hline & \multirow[t]{2}{*}{ Location of termination } & Same as bending break & 5 & 3 \\
\hline & & Opposite to bending break & 2 & 2 \\
\hline \multicolumn{3}{|c|}{ Total Secondary damage } & 7 & 4 \\
\hline \multirow[t]{12}{*}{ Lateral scars } & \multirow[t]{2}{*}{ Fracture composition } & Simple & 5 & 3 \\
\hline & & Multiple & 2 & 2 \\
\hline & \multirow[t]{2}{*}{ Initiation } & Absent & 0 & \\
\hline & & Present & 7 & 4 \\
\hline & \multirow[t]{3}{*}{ Initiation morphology } & Cone & 0 & 0 \\
\hline & & Bending & 7 & 4 \\
\hline & & Intermediate & 0 & 0 \\
\hline & \multirow[t]{2}{*}{ Fissure of termination } & Yes & 0 & 0 \\
\hline & & No & 7 & 4 \\
\hline & \multirow{3}{*}{$\begin{array}{l}\text { General direction with regard to } \\
\text { the axis of the piece }\end{array}$} & Oblique & 7 & 4 \\
\hline & & Variable & 0 & 0 \\
\hline & & Perpendicular & 0 & 0 \\
\hline \multicolumn{3}{|l|}{ Total Lateral scars } & 7 & 4 \\
\hline \multicolumn{3}{|l|}{ Total } & 21 & 5 \\
\hline
\end{tabular}

Table 11 Details of the fracture attributes for pieces identified as projectile element for locus LB57A.

Possible hafting glue was observed on the lateral backed edge of two identified projectile elements (LB57A.1973-1c (cf. Figure 14); LB57A.5080-4871-30-1c (cf. Figure 15)). The arguments for interpreting these residues as a possible hafting glue are their exclusive location on the backed edge of the tools and their high organic composition as revealed by SEM-EDS analysis with a significant peak of carbon (C) while other elements such as calcium (Ca), aluminium (Al) and potassium (K) are present in much lower quantities. 


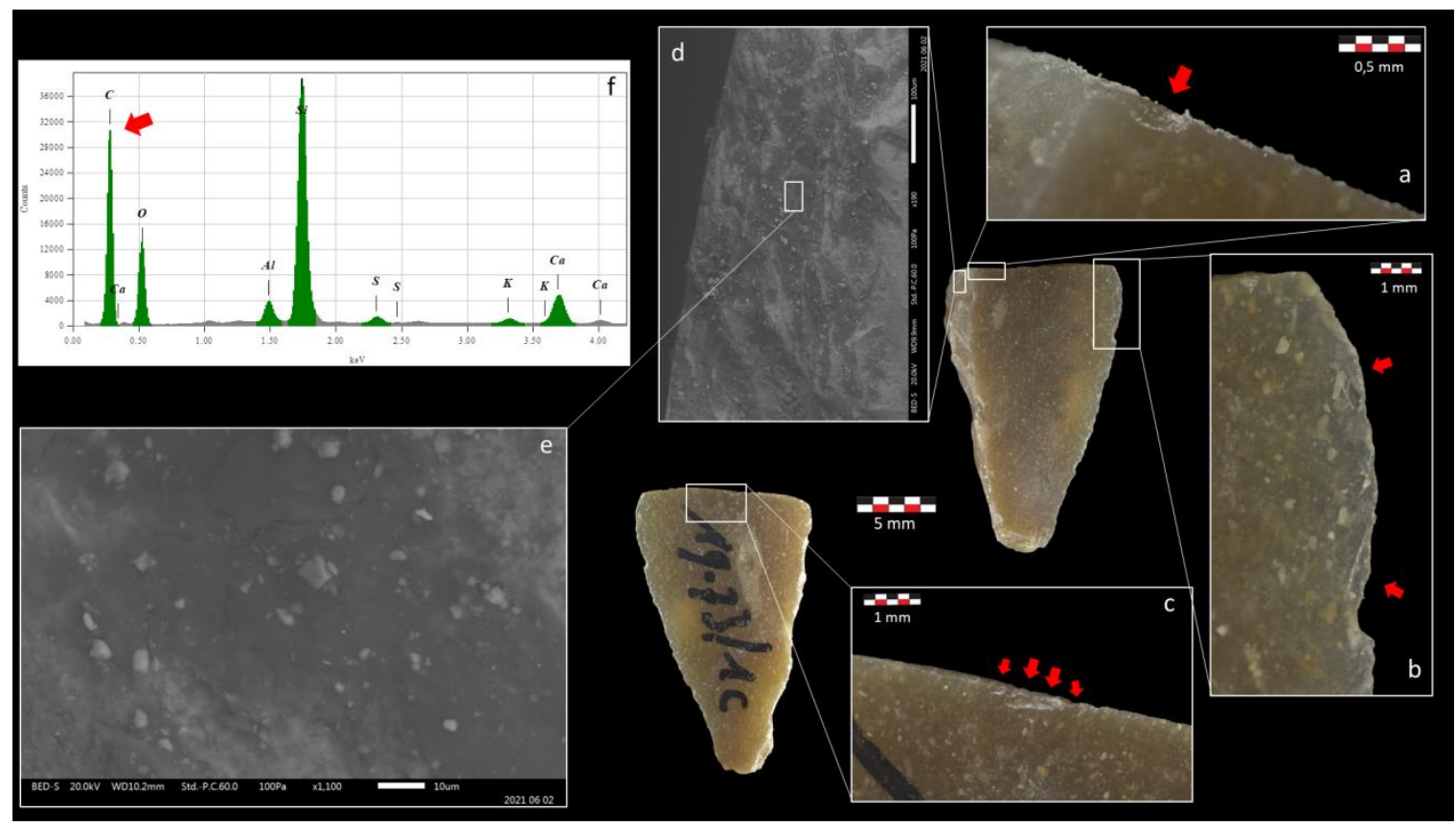

Figure 14 Macroscopic details of the impact damage present on the curved backed piece LB57A.1973-1c which permitted it to identify it as a possible projectile fragment, but the combination of traces was insufficient to be fully certain. The piece presents a combination of : $a)+b$ ) bending breaks, secondary damage and; b) oblique oriented lateral scars in opposite directions (b). Possible hafting glue observed on the back: (d) backscattered electron image showing its presence on the backed edge of the tool (e) detail of the amorphous organic residue, showing no distinctive features (f) elemental analysis of the residue, indicating the highly organic composition of the residue as illustrated by the abundant presence of carbon (indicated with red arrow).

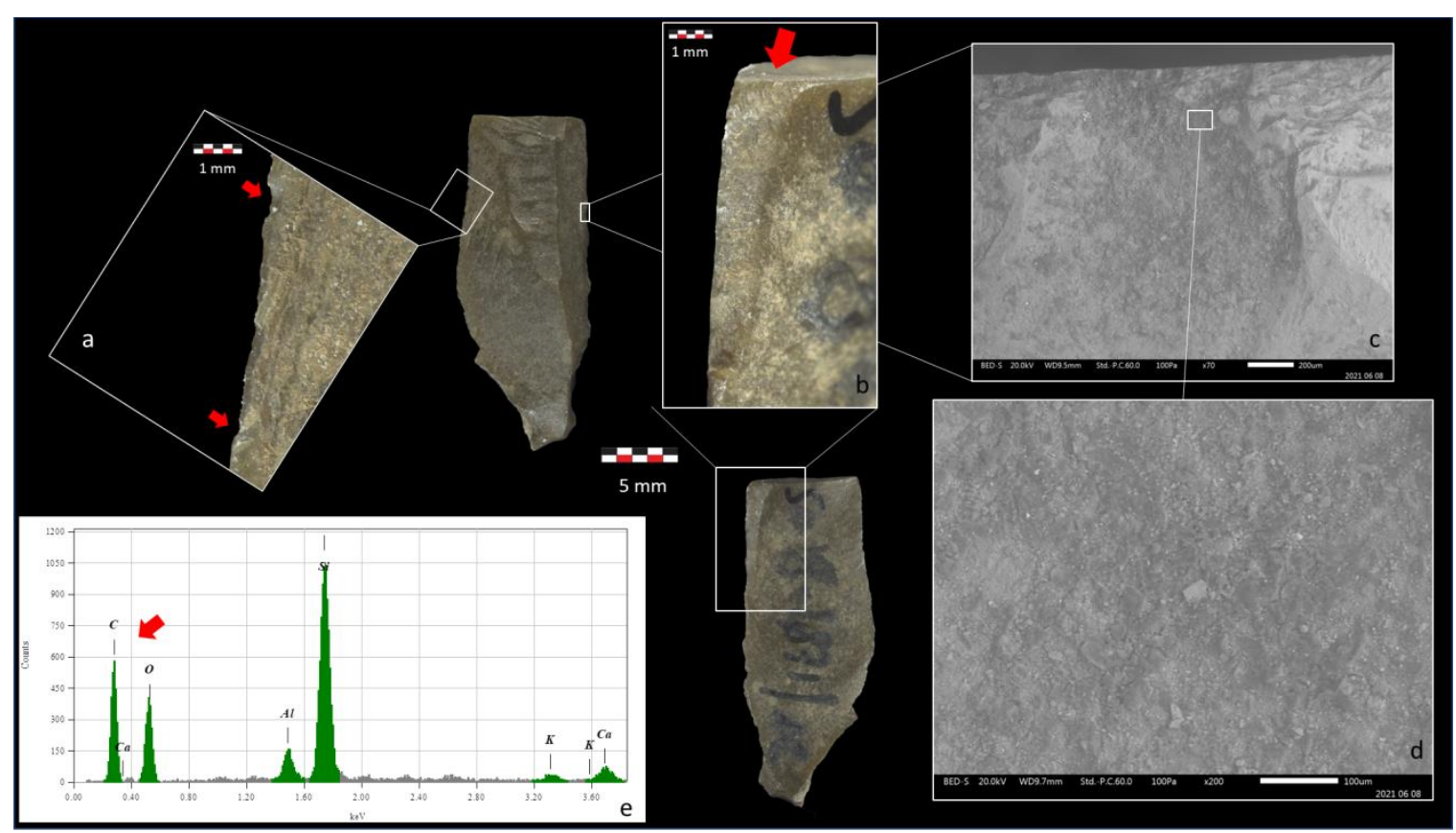

Figure 15 Macroscopic details of the impact damage present on the curved backed piece LB57A.518-4871-1c identified as a projectile element. The piece presents a combination of: a) obliquely oriented lateral scarring and; b) a hinge-terminating bending break with a long propagation phase on the right lateral side. Possible hafting glue observed on the back: c) backscattered electron image showing its presence on the backed edge of the tool; d) detail of the amorphous organic residue, showing no distinctive features; e) elemental analysis of the residue, indicating the high organic composition of the residue with an important presence of carbon (indicated with red arrow). 


\subsubsection{Evaluation of propulsion mode}

Trying to determine the propulsion mode used requires the incorporation of a morphological and morphometric study of the points, an evaluation of the mechanical stress responsible for the impact fractures, an evaluation of the hafting system and an experimental testing of the hypotheses (e.g., Coppe 2020).

\subsubsection{Morphology of the points}

Morphological and morphometric data were only recorded for the identified projectile elements ( $N=27)$ of LB25 and points without indubitable evidence of use as projectile element were thus excluded. Maximal thickness and width were recorded, but due to the important degree of fragmentation, the maximal length could only be recorded for three pieces. In general, points are thin and narrow (cf. Table 12) but dimensions vary within the assemblage. Points are manufactured on bladelets and present a curved backed edge. Backs are mostly made by direct retouch and marginally crossed retouch shapes the apical part. Retouch on the back is rather limited and non-invasive. Only two pieces present non-invasive direct abrupt retouch on the proximal base. The curve of the back is installed by an inflexion point that is generally placed in the first third of the piece, starting from the apex. The pieces present a sharp natural cutting edge.

\begin{tabular}{|c|c|c|c|c|c|c|}
\hline Labels & $\begin{array}{l}\text { Max } \\
(\mathrm{mm})\end{array}$ & length & $\begin{array}{l}\text { Max thickness } \\
\text { (mm) }\end{array}$ & $\begin{array}{l}\text { Max } \\
(\mathrm{mm})\end{array}$ & width & $\begin{array}{l}\text { Cross-section } \\
\left(\mathrm{mm}^{2}\right)\end{array}$ \\
\hline Min & 30.1 & & 1.6 & 3.6 & & 2.88 \\
\hline Median & 39 & & 4.5 & 10.9 & & 25.9 \\
\hline Max & 64.6 & & 6.2 & 14.4 & & 39.06 \\
\hline
\end{tabular}

Table 12 Summary of the morphological variation in the identified projectile sample.

\subsubsection{Experiment}

Thirty experimental tools (experiment 112 of TRAIL) were manufactured with similar morphologies and metrics to the archaeological ones (cf. Figure 16 and Table 13) by an experienced knapper (C. Lepers, TraceoLab) out of flint from the Harmignies quarry. Each point was photographed in detail before the experiment to register all production damage. The pieces were subsequently hafted in a split wooden shaft with a disto-lateral orientation (cf. Figure 14) with the aid of a glue consisting of $70 \%$ spruce resin (Epicea) and $30 \%$ beeswax. The recovered likely glue residues confirm the relevance of this hafting system (see above). Projectiles were shot by one of the authors (J. Coppe, 10 years of experience as archer) with a forty-eight-pound bow and a draw distance of twenty-nine inches in an artificial target. Tests have demonstrated that draw length (and in direct consequence the kinetic energy deployed by the bow) of J. Coppe is similar to that of $C$. Lepers who performed the other bow-and-arrow experiments of TRAIL. The kinetic energy deployed by the bow is around $30 \mathrm{~J}$ (for measurement details, see Coppe et al. 2019). The artificial target was made out of a block ( $40 \mathrm{~cm} \times 40 \mathrm{~cm} \times 60 \mathrm{~cm}$ ) of $10 \%$ ballistic gelatin 
(Fackler and Malinowski 1985; Jussila 2004) according to the procedures detailed in (Coppe and Rots 2017). The block contained ribs that were positioned at two $\mathrm{cm}$ from the outer surface of the block. The target was covered by a rehydrated deerskin that was stretched with Sandow elastics. The arrows were shot until they showed a first fracturing phenomenon or when they dehafted, with a maximum of ten shots per arrow.

Since only the bow was used for propulsion, results are by definition preliminary and require further confirmation through the incorporation of other propulsion modes. However, TRAIL contains other experimental backed points shot with the four standard propulsion modes (thrusting, throwing, spear-thrower, and bow), the study of which permitted several important insights (e.g., Coppe 2020) and these experiences served as a general framework for the study of Lommel-Maatheide.

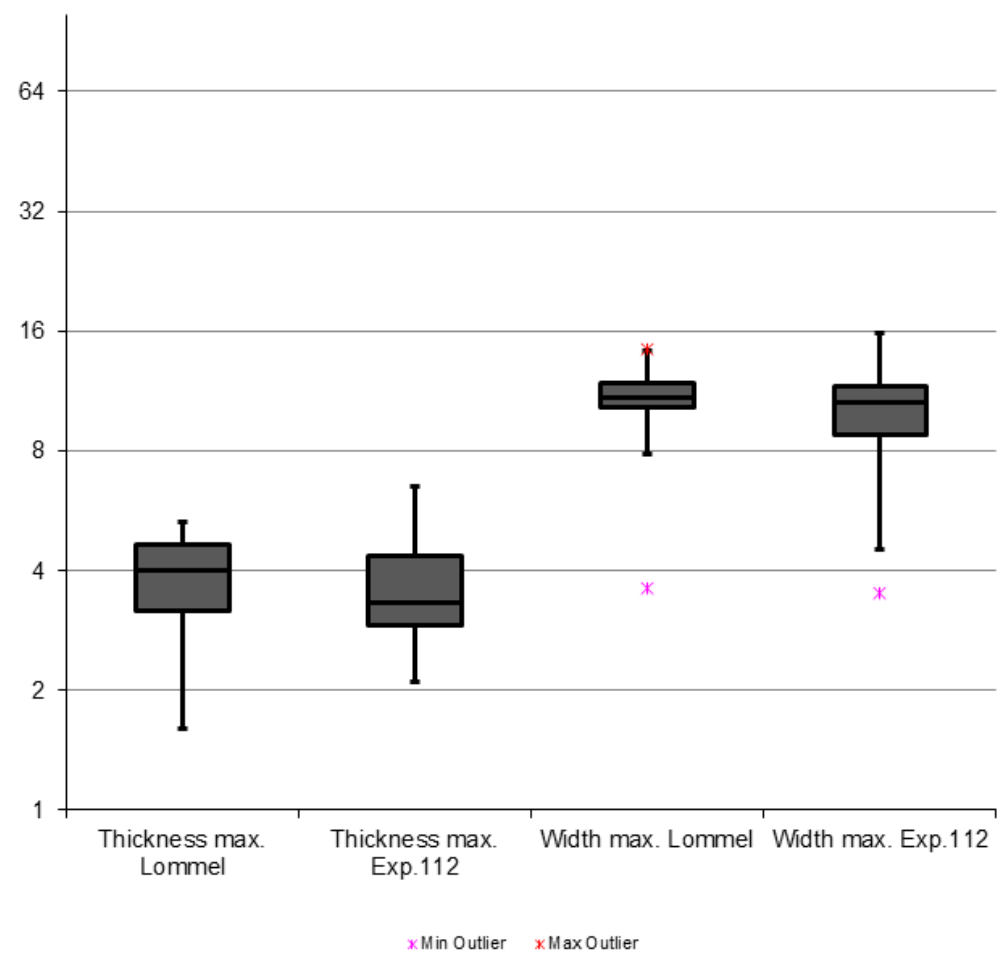

Figure 16 Boxplot comparing the morphological variations between the curved backed points from Lommel-Maatheide identified as projectiles and their experimental reproductions. 


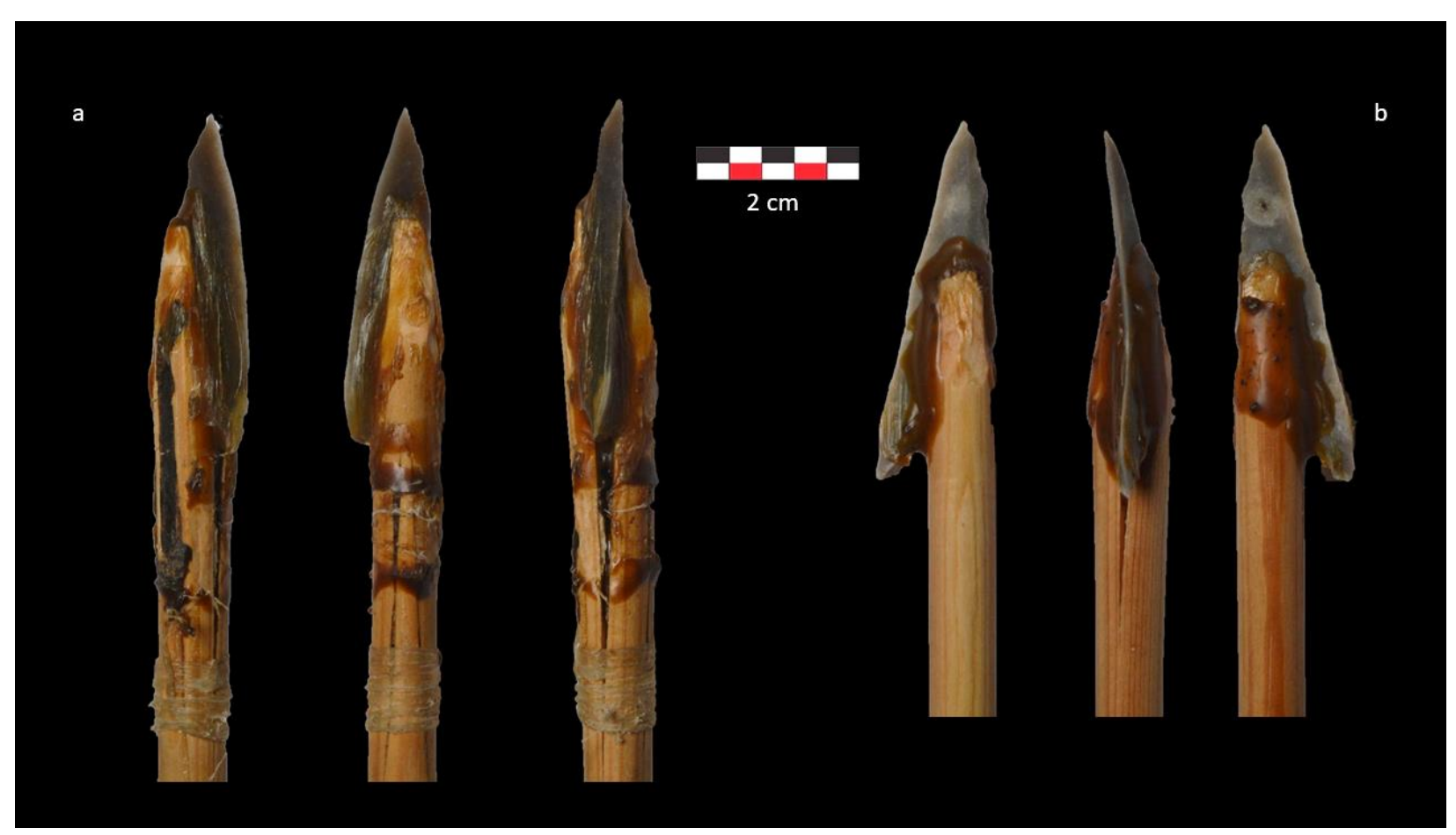

Figure 17 Experimentally reproduced and hafted curved backed points: a) Exp112_07 and b) Exp112_13.

\begin{tabular}{|c|c|c|c|c|c|}
\hline Labels & $\begin{array}{l}\text { Maximal thickness } \\
\text { Maatheide }\end{array}$ & Lommel- & $\begin{array}{l}\text { Maximal thickness } \\
\text { Exp.112 }\end{array}$ & $\begin{array}{l}\text { Maximal width Lommel- } \\
\text { Maatheide }\end{array}$ & $\begin{array}{l}\text { Maximal width } \\
\text { Exp.112 }\end{array}$ \\
\hline Min & 1,6 & & 2,1 & 3,6 & 3,5 \\
\hline $\mathbf{Q}_{1}$ & 3,15 & & 2,9 & 10,25 & 8,8 \\
\hline Median & 4 & & 3,3 & 10,9 & 10,6 \\
\hline $\mathbf{Q}_{3}$ & 4,65 & & 4,35 & 11,85 & 11,65 \\
\hline Max & 5,3 & & 6,5 & 14,4 & 15,8 \\
\hline IQR & 1,5 & & 1,45 & 1,6 & 2,85 \\
\hline Upper Outliers & 0 & & 0 & 1 & 0 \\
\hline Lower Outliers & 0 & & 0 & 2 & 1 \\
\hline
\end{tabular}

Table 13 Summary of the morphometrical variation between the identified projectile points from Lommel-Maatheide LB25 and the experimental reproductions

Twenty pieces impacted the target and each contact with the ribs inside the target resulted in a breakage of the point or the hafting arrangement. The weapon design proved efficient as the penetration depth of the arrows was profound (average $19 \mathrm{~cm} ; \min .5 \mathrm{~cm}-\max .33 \mathrm{~cm}$ ) and no dehafting without penetration of the skin was observed, indicating a reliable hafting arrangement.

The number of fractures obtained during the experiment and the proportions between the four categories of fractures are consistent with an application of compression-oriented stress and extremely similar to what was observed for the archaeological sample (cf. Table 14). 


\subsubsection{Evaluation}

The fracture patterns observed on the points of LB25 reveal several elements of the weapon system used. The high proportion of pieces with fractures associated with at least one secondary damage feature (67\%) and with oblique lateral scarring (89\%) indicates that these projectiles have been exposed to an important compressive stress during fracturing (cf. Table 14). In addition, $46 \%$ of the secondary damage features (16/35) and $25 \%$ of the lateral scaring features (21/ 84) present fissured terminations. In terms of the propulsion mode, the signature that we observe on the projectile elements from LB25 is close to what we could observe on experimental pieces propelled with a bow within TRAIL (cf. Table 15). This hypothesis also fits with the result obtained in a recent ballistic investigation (Coppe et al. submitted) identifying the bow as the weapon system presenting the highest compressive component in his reactional impact stress (the stress responsible for fracturing the point during impact).

However, oriented lateral scarring is particularly low in number on TRAIL pieces in comparison with the archaeological material of LB25 (cf. Table 15). An explanation likely need to be sought in the exclusively axial hafting orientation used in the relevant experimental reference set of TRAIL (Coppe and Rots 2017 Fig.8a,p.116). A minor change in armature orientation within the haft could significantly increase the proportion of oriented lateral scars. An apical oblique orientation within the haft increases the exposure of the lateral cutting edge to a contact with animal bones during impact and thereby increases the number of possible lateral scars. Interestingly, this type of orientation seems in perfect correspondence with the morphological characteristics of this type of curved backed point and it was proposed previously (Plisson 2005 Fig.2, p.186).

\begin{tabular}{|c|c|c|c|c|c|c|c|c|c|c|}
\hline & \multicolumn{2}{|c|}{ Bending Breaks } & \multicolumn{2}{|c|}{ Secondary damage } & \multicolumn{2}{|c|}{ Oblique lateral scars } & \multicolumn{2}{|c|}{$\begin{array}{l}\text { Perpendicular } \\
\text { lateral scars }\end{array}$} & \multicolumn{2}{|l|}{ Total } \\
\hline & N. point & $\mathrm{N}$ fract. & N. point & $\mathrm{N}$ fract. & N. point & $\mathrm{N}$ fract. & $\begin{array}{l}\mathrm{N} . \\
\text { point }\end{array}$ & $\begin{array}{l}\mathrm{N} \\
\text { fract. }\end{array}$ & $\begin{array}{l}\mathrm{N} \\
\text { point }\end{array}$ & $\begin{array}{l}\mathrm{N} \\
\text { fract. }\end{array}$ \\
\hline Lommel & 24 & $35(23 \%)$ & 18 & 35 (23\%) & $24(89 \%)$ & $76(49 \%)$ & 8 & $8(5 \%)$ & 27 & 154 \\
\hline LB25 & (89\%) & & $(67 \%)$ & & & & $(30 \%)$ & & & \\
\hline Exp112 & $\begin{array}{l}13 \\
(65 \%)\end{array}$ & $19(24 \%)$ & $8(40 \%)$ & $21(26 \%)$ & $16(80 \%)$ & 35 (44\%) & $\begin{array}{l}3 \\
(15 \%)\end{array}$ & $2(3 \%)$ & 20 & 79 \\
\hline
\end{tabular}

Table 14 Comparison of the number of pieces affected by at least one fracture category and the number of fractures between the identified projectile elements of Lommel-Maatheide and the new experimental reference. 


\begin{tabular}{|c|c|c|c|c|c|}
\hline & $\begin{array}{l}\text { Bow } \\
\text { N Ind. }\end{array}$ & $\begin{array}{l}\text { Spear-thrower } \\
\qquad \text { N Ind. }\end{array}$ & $\begin{array}{l}\text { Throwing spear } \\
\qquad \text { N Ind. }\end{array}$ & $\begin{array}{l}\text { Thrusting spear } \\
\text { N Ind. }\end{array}$ & N Ind. \\
\hline Bending Breaks & $16(100 \%)$ & $13(93 \%)$ & 15 (83\%) & 15 (79\%) & $24(89 \%)$ \\
\hline Secondary damage & 13 (81\%) & $5(36 \%)$ & 11 (61\%) & $8(42 \%)$ & $18(67 \%)$ \\
\hline $\begin{array}{l}\text { Oblique lateral } \\
\text { scars }\end{array}$ & $7(44 \%)$ & $6(43 \%)$ & $9(50 \%)$ & $11(58 \%)$ & 24 (89\%) \\
\hline $\begin{array}{l}\text { Perpendicular } \\
\text { lateral scars }\end{array}$ & $4(25 \%)$ & $4(29 \%)$ & $2(11 \%)$ & $1(5 \%)$ & $8(30 \%)$ \\
\hline Total & 16 & 14 & 18 & 19 & 27 \\
\hline
\end{tabular}

\section{Discussion}

In the past, functional analysis has made a significant contribution to the understanding of Late Glacial settlement dynamics thanks to applications on meticulously excavated, wellpreserved and homogenous lithic assemblages from Federmessergruppen sites such as Rekem and Meer (De Bie and Caspar 2000; Van Noten 1978). Assemblages of that quality are unfortunately rare and one therefore also needs to consider other, less pristine contexts to evaluate whether a functional analysis would permit similar high-resolution data. The Federmessergruppen site of Lommel-Maatheide lends itself perfectly to evaluate this question as it extends over a vast area and it is characterised by a broad variety in preservation states, within and between concentrations.

\subsection{Potential biases induced by taphonomy or excavation}

The impact of post-depositional processes proved to vary between and within concentrations which needs to be taken into account as it may lead to bias in terms of the functional understanding of the site. In general, the preservation state proved to be determined mainly by the location of the concentration within the Late Glacial topography. Concentrations located on the eroded dune ridge (LB25, LB38) showed a relatively poor degree of preservation due to aeolian erosion (i.e., sandblasting and transport by wind), witnessed by the abundant presence of an intense gloss and extensive edge rounding and damage. These alterations particularly hampered observations under reflected-light microscopy of wear traces such as striations or polishes (Keeley 1980; Vaughan 1985). As a result, tool use or hafting could be identified on a relatively low number of tools only, which hampers the identification of the activities that took place at these locations. By contrast, the identification of projectiles proved less hampered by these alterations, as it mainly relied on damage patterns, at the exception of cases in which the alteration also heavily affected the edges. 
The concentrations located at the base (LB57A) or the north side of the dune ridge (LB01, LB60) appear to have been quickly covered by sediment eroding from the dune (De Bie and Van Gils 2004) and the material is much better preserved. Thanks to the good preservation of wear traces, the worked materials and the presence of hafting could be identified with a higher degree of confidence for these concentrations. However, several artefacts proved to have been impacted by other taphonomic processes such as exposure to heat or soil acidity (Burroni et al. 2002) which hampered functional interpretation after all.

In comparison to sometimes severe taphonomic alterations, the impact of (post-) excavation strategies proved minimal and did not really hinder the use-wear analysis. Moreover, it could be established that the excavation itself contributed to more important formation of metal wear than sieving, at least for the sieving protocol used at Lommel-Maatheide. Indeed, sieving most often resulted in sparse and very fine metal striations, while contact with excavation equipment was more intense, generally combining edge damage with clearly visible, wide metal striations.

Residue analysis revealed that the soil acidity played a major factor in residue preservation as only residue types (terpenes (plant resins), carbohydrates (plant), possible lipids (fat)) resistant to such well-drained, acidic soil conditions preserved (Cnuts 2021; Langejans 2010). It further explains the absence of hydroxyapatite (bone mineral) residues which probably dissolved due to the highly acidic soil conditions (Cnuts 2021; Hedges 2002; High et al. 2015), as it is also the case with the faunal remains at Lommel-Maatheide. The poor preservation potential of bone mineral residues within such acidic soil conditions is best illustrated by the absence of apatite residues on the burins of LB01 that were used for grooving/shaving antler.

\subsection{Activities, tool use and hafted technologies}

Despite severe taphonomic alterations for some concentrations and an inadequate selection strategy for one other concentration, it proved possible to identify a range of activities that took place at the site of Lommel-Maatheide. Identified activities include the processing of soft plants, hide scraping, antler working, projectile maintenance and hunting. Certain activities remained identifiable in spite of severe alterations, such as projectile use for LB25 thanks to preserved macroscopic damage and hide working for LB25 thanks to a preserved strong edge rounding of the scraper-head of endscrapers. The better-preserved concentrations (LB57A and LB01) revealed additional microscopic wear features such as the abrasive striations associated with plant polish or the striations from antler working. These results underline the importance of systematic functional analyses to reconstruct activities that took place at a site, in particular when only stone tools are preserved as is the case for Lommel-Maatheide.

The identification of soft plant processing at Lommel-Maatheide contributes to the growing body of evidence for soft plant processing tools (mainly unmodified blanks, but also burins and a retouched blade) from the Late Glacial period (including from Federmessergruppen sites) (Barton et al. 2009; Jacquier 2014; Sobkowiak-Tabaka and Kufel-Diakowska 2019), which suggests that 
plant processing is probably a more common activity during the end of the Late Glacial period than previously assumed. Here, wear from a transversal use on plants was observed on two endscrapers, which is highly suggestive for the processing of bast fibres such as flax, nettle or hemp (Caspar et al. 2005; Van Gijn and Mazzucco 2013). Despite numerous experiments (e.g. (Caspar et al. 2005; Hurcombe 2008; Jensen 1994; Osipowicz 2019; Vaughan 1985) it remains difficult to ascertain the exact nature of plant processing activities because the range of variation is not yet fully understood and traces from working different kinds of plant materials may appear quite similar. On the contrary, hide scraping and antler working are considered common activities on Federmesser sites (e.g. Meer II (Van Noten 1978) and Rekem (De Bie and Caspar 2000)). Here, the variation in use-wear traces from hide scraping enabled the identification of different phases in the hide working process: from cleaning wet hides (removal of fat and other undesirable parts) up to currying dry hide (softening and changing the outer part of the texture) (Beyries and Rots 2008; Keeley 1980; Moss 1983; Semenov 1964). Also soaked antler proved to have been worked at Lommel-Maatheide, involving the local production of the stone tools. The exact reason why antler was worked cannot be determined and the working motion (grooving or shaving) could be useful in many tasks, including point production or decorative carving. In addition, refitting showed that the burins from LB01 were manufactured and resharpened in that area (De Bie et al. 2003), which permits to interpret these tools as examples of situational gear (Binford 1979), being tools that appear to have been manufactured at the site in response to an immediate need (i.e., shaving soaked antler) (see also Tomasso and Rots 2021). Furthermore, the functional analysis allowed to identify resharpening for the burins and scrapers but no evidence for secondary use or recycling could be observed. This may be because occupations were relatively short-term with mobile hunter-gatherer groups that occupied a much larger territory.

The low number of identified projectiles (e.g. LB 25: $27 / 254=10,6 \%$ ) is furthermore suggestive of retooling activities that may have taken place at the site. The importance of the manufacture of points, the repair of weaponry and the discard of used and fractured projectiles is something that was also observed at other Federmessergruppen sites, such as Rekem (Caspar and De Bie 1996).

The study of hafting wear also indicates that hafting was well-integrated into the technical system and hafted tools were involved in each of the identified domestic activities. Hafting wear was, however, not very well-developed which hampered a reconstruction of the hafting arrangements. The limited presence of hafting wear is partly due to the preservation state of the material but may also be explained by the use of hafting glue, which limits the development of hafting wear (Rots 2002). The observation of likely glue residues through SEM-EDS on two projectile elements from LB57A suggests that expertise for glue production might have been available. A further characterization with gas chromatography and mass spectroscopy is required to further confirm that these residues are effectively glue remains and to determine their molecular composition. The presence of, for instance, terpenes and terpenoids would permit a 
further identification as plant resin (Cnuts, Perrault, et al. 2018; Langenheim 2003; Regert 2004). This characterization is part of an on-going study.

\subsection{Projectiles and the understanding of Federmessergruppen hunting technology}

The identification of curved backed points as projectiles and their overall predominance confirms their fundamental role in the weapon systems employed by the inhabitants of the site and this patterns likely extends to other Federmessergruppen assemblages (Caspar and De Bie 1996). The projectile analysis has not only led to the identification of 27 used projectile points but a pilot study of the propulsion mode could also be performed leading to the proposition of a first hypothesis for the mode of propulsion and the orientation of the point in the hafting system. Even if results are still somewhat preliminary, the results are suggestive for the use of bow-and-arrow with armatures positioned in an apical oblique hafting system, pending confirmation through an experimental program that includes different weapon systems and not the bow exclusively. Probable use of the bow by Federmessergruppen in Belgium is not new and was previously proposed for the curved backed points of Rekem based on the size of the projectiles and their degree of damage (Caspar and De Bie 1996). Our study lends further support to this interpretation.

\subsection{Site function and organisation}

Combining the results from this larger-scale functional analysis with geographical data would permit reflecting on broader behavioural questions such as settlement patterns or land use (Anschuetz et al. 2001; Binford 1978, 1980; Gron and Kuznetsov 2004) of Federmessergruppen. The assessment of such broader questions based on results from LommelMaatheide proved to be challenging and different problems were encountered. First, there is the palimpsest problem as the contemporaneity of the different loci cannot be established with certainty in the absence of refitting evidence among the loci. Moreover, it is not clear for the majority of concentrations whether they result from one single occupation event or an accumulation of repeated visits of these Federmessergruppen (De Bie et al. 2009; De Bie and Van Gils 2009). Furthermore, there is a strong variation in preservation states between the different concentrations, resulting in a bias in terms of the functional understanding of these different locations. Situated on top of the dune, the artefacts from LB25 proved to be heavily affected by taphonomic processes, resulting in a low number of identified tool uses aside from the projectiles. As a consequence, it remains unclear whether the remaining tools were part of the same hideprocessing toolkit or involved in other activities. On the other hand, as the identified activities only include animal-related tasks such as hide cleaning/curing or projectile maintenance, it may be assumed that they were the predominant activities at this location. By contrast, concentration LB01 proved to be minimally impacted by taphonomy and the exclusive presence of burins here 
suggests that these are the remains of a single-occupation event, more specifically the shaving of soaked antler. The three remaining concentrations are more difficult to interpret as no clear tool use could be identified in case of concentration LB38/LB60 or only a very limited number (N=2) of tool uses could be identified (LB57A).

Earlier studies (De Bie et al. 2009; De Bie and Van Gils 2009; Derese et al. 2012) have attempted to reconstruct long-term land-use patterns for the site of Lommel-Maatheide based on typo-technological, geomorphological and palaeoecological data. As the site was located on a large Late Glacial sand ridge on the northern edge of a shallow lake, it provided a strategic viewpoint over the lake for monitoring game. Functional analysis contributed to the role of each concentration within the general intra-site activity pattern at Lommel-Maatheide. It is not a coincidence that the largest concentration (LB25) is situated on top of the dune, providing a strategic viewpoint over the lake. The predominant presence of residential activities such as hide working or retooling confirms the significance of this location within the landscape. The small concentration north of the dune (LB01) is not directly linked with the Late Glacial lake and served as a specialised activity zone for shaving soaked antler, away from the main residential settlement. The presence of plant processing on the lake's fringes (LB57A), while such evidence was absent from all other studied concentrations, indicates that locally grown plants were exploited on the spot. In general, it seems that the proximity to water plays a major role in determining the location of the different activities at Lommel-Maatheide and should be considered a key element in understanding the organisation of this site. Future functional analysis is needed to verify whether similar patterns can be observed at other sites in the Campine region.

\subsection{Possibilities of eroded landscapes for functional analysis and future directions}

A detailed taphonomic analysis of the stone tools combined with geomorphological and palaeoecological data allowed assessing accurately the possibilities for functional analysis of the different loci within the eroded dune landscape. It allowed demonstrating that the position within the dune landscape (and in particular its taphonomic history) is crucial in the surface preservation of stone tools as lithics from the eroded top of the dune were severely altered by aeolian processes, whereas lithics away from the top proved to be well preserved as they were quickly covered by eroded sands. Altered stone tools from the top of the dune could mainly be studied for macroscopic edge damage, whereas the well-preserved stone tools away from the top also proved suitable for a more detailed use-wear study. For poorly preserved material, it proved important to screen a larger selection of material in order to increase the chance of detecting stone tools with distinctive use-wear.

Although the current study has revealed important information on the activities and site organisation, future research is needed to confirm that the different locations served different purposes through an even more systematic study of all stone tools. 


\section{Conclusion}

In this paper, the results of an elaborate and integrated functional analysis of the Federmessergruppen assemblages of Lommel-Maatheide have been presented. The main goal of the study was to assess the potential of relatively poorly preserved contexts for functional interpretations and to systematically evaluate the impact of taphonomic processes and excavation protocols on the preservation of wear traces and residues. It was demonstrated that withminor adjustments of the analytical methods, high-resolution data are attainable. Indeed, new insights could be proposed for the activities performed at the site, including the processing of vegetal materials, likely fibres, soft and hard animal materials, and hunting activities. These activities proved to be localised in specific sections of the site and seemed to be strongly linked with the position of the concentration within the Late Glacial dune landscape. In addition, the application of a newly developed methodology with regard to projectiles permitted to propose a hypothesis for the weapon design and the propulsion mode, in this case the bow, thereby highlighting essential parts of the hunting technology of Federmessergruppen. The highly detailed and innovative results of this study provided new insights into Federmessergruppen huntergatherer societies and underlined the importance of studying assemblages that are spread over vast land surfaces, even when available contextual data are less fine-grained.

\section{Acknowledgements}

This research was supported by funding from the Flemish Goverment, Belgium, in the framework of archaeological synthesis research (Projectsubsidie archeologisch syntheseonderzoek). The research was part of a broader research project focussing on the functional investigation of Final Palaeolithic and Early Mesolithic sites in Flanders. We thank Christian Lepers for his assistance in the experiments. Veerle Rots is indebted to the FNRS-FRS. We are also indebted to the University of Liège for their support of this research. 


\section{Bibliography}

Anschuetz, K., Wilshusen, R., \& Scheick, C. (2001). An Archaeology of Landscapes: Perspectives and Directions. Journal of Archaeological Research, 9(2), 157-211. doi:10.1023/A:1016621326415

Asryan, L., Ollé, A., \& Moloney, N. (2014). Reality and confusion in the recognition of postdepositional alterations and use-wear: an experimental approach on basalt tools. Journal of Lithic Studies, 1(1), 9-32. doi:10.2218/jls.v1i1.815

Asryan, L., Ollé, A., Moloney, N., King, T., \& Murray, J. (2017). Chemical Alteration of Lithic Artefacts: an Experimental Case Study on the effect of Guano on Stone Flakes and Its Contextualization in the Archaeological Assemblage of Azokh Cave (Southern Caucasus). Archaeometry, 59(6), 981-999. doi:10.1111/arcm.12300

Barton, N., Ford, S., Collcut, S., Crowther, J., Macphail, R., Rodhes, E., \& Van Gijn, A. (2009). A Final Upper Palaeolithic site at Nea Farm, Somerley, Hampshire (England) and some reflections on the occupation of Britain in the Late Glacial Interstadial. Quartar, 56, 1-29. doi:10.7485/QU56_01

Beugnier, V., \& Crombé, P. (2005). Étude fonctionnelle du matériel en silex du site mésolithique ancien de Verrebroek (Flandres, Belgique): Premiers résultats. Bulletin de la Societe Prehistorique Francaise, 102(3), 527-538. doi:10.3406/bspf.2005.13140

Beyries, S., \& Rots, V. (2008). The contribution of ethno-archaeological macro- and microscopic wear traces to the understanding of archaeological hide-working processes. In Prehistoric technology: 40 years later: functional studies and the Russian legacy (pp. 21-28).

Binford, L. R. (1978). Dimensional Analysis of Behavior and Site Structure: Learning from an Eskimo Hunting Stand. American Antiquity, 43(3), 330-361. doi:10.2307/279390

Binford, L. R. (1979). Organization and Formation Processes: Looking at Curated Technologies. Journal of Anthropological Research, 35(3), 255-273. doi:10.1093/jsh/shr033

Binford, L. R. (1980). Willow smoke and dogs' tails: hunter-gatherer settlement systems and archaeological site formation. American antiquity, 45(1), 4-20.

Burroni, D., Donahue, R. E., Pollard, A. M., \& Mussi, M. (2002). The Surface Alteration Features of Flint Artefacts as a Record of Environmental Processes. Journal of Archaeological Science, 29(11), 1277-1287. doi:10.1006/jasc.2001.0771

Cahen, D., Keeley, L. H., \& Noten, F. L. Van. (1979). Stone Tools, Toolkits, and Human Behavior in Prehistory. Current Anthropology, 20(4), 661. doi:10.1086/202371

Caspar, J.-P., \& De Bie, M. (1996). Preparing for the hunt in the late paleolithic camp at rekem, Belgium. Journal of Field Archaeology, 23(4), 437-460. doi:10.1179/009346996791973747

Caspar, J.-P., Féray, P., \& Martial, E. (2005). Identification et reconstitution des traces de teillage des fibres végétales au Néolithique. Bulletin de la Societe Prehistorique Francaise, 102(4), 867-880. doi:10.3406/bspf.2005.13188

Cnuts, D. (2021). Appreciating the little things. Possibilities and challenges of stone tool residue analysis in reconstructing Late Pleistocene technologies. Université of Liège.

Cnuts, D., Perrault, K., Stefanuto, P.-H., Dubois, L., Focant, J.-F., \& Rots, V. (2018). Fingerprinting Glues Using HS-SPME GCXGC-HRTOFMS: a New Powerful Method Allows Tracking Glues Back in Time. Archaeometry, 60(6), 1361-1376. doi:10.1111/arcm.12364

Cnuts, D., \& Rots, V. (2017). Taphonomie et analyse des résidus sur les pièces lithiques. In J.-P. Brugal (Ed.), Taphonomies (Sciences A., pp. 187-194). Paris: Éditions des archives 
contemporaines.

Cnuts, D., \& Rots, V. (2018). Extracting residues from stone tools for optical analysis: towards an experiment-based protocol. Archaeological and Anthropological Sciences, 10(7), 1717-1736. doi:10.1007/s12520-017-0484-7

Cnuts, D., Tomasso, S., \& Rots, V. (2018). The Role of Fire in the Life of an Adhesive. Journal of Archaeological Method and Theory, 25(3), 839-862. doi:10.1007/s10816-017-9361-z

Coppe, J. (2020). Sur les traces de l'armement préhistorique: Mise au point d'une méthode pour reconstruire les modes d'emmanchement et de propulsion des armatures lithiques par une approche expérimentale, mécanique et balistique. Université de Liège, Liège, Belgique.

Coppe, J., Lepers, C., Clarenne, V., Delaunois, E., Pirlot, M., \& Rots, V. (2019). Ballistic Study Tackles Kinetic Energy Values of Palaeolithic Weaponry. Archaeometry, (November 2018). doi:10.1111/arcm.12452

Coppe, J., \& Rots, V. (2017). Focus on the target. The importance of a transparent fracture terminology for understanding projectile points and projecting modes. Journal of Archaeological Science: Reports. doi:10.1016/j.jasrep.2017.01.010

Coppe, J., Lepers, C. \& Rots, V. (N.D.). Projectiles under a new angle. A ballistic analysis provides an important building block to grasp Paleolithic weapon technology. Submitted.

Creemers, G., \& Carolus, J. (1989). Epipaleolithicum te Lommel-Blokwaters. Limburg, 68, 195200.

Croft, S., Monnier, G., Radini, A., Little, A., \& Milner, N. (2016). Lithic residue survival and characterisation at star carr: A burial experiment. Internet Archaeology, (42), 4DUMMY. doi:10.11141/ia.42.5

De Bie, M., \& Caspar, J.-P. (1997). La signification des outillages lithiques dans les industries à Federmesser [Observations sur la variabilité des burins et des pièces laminaires ou lamellaires à modification latérale dans le gisement de Rekem (Belgique)]. Bulletin de la Société préhistorique française, 94(3), 361-372. doi:10.3406/bspf.1997.10700

De Bie, M., \& Caspar, J.-P. (2000). Rekem; a 'Federmesser'Camp on the Meuse River Bank (2 Vols). Leuven University Press and Instituut voor het Archeologisch Patrimonium. Leuven \& AsseZellik.

De Bie, M., Gullentops, F., \& Van Gils, M. (2003). Een Laat-Paleolithische concentratie in een Usselo-bodem op de Maatheide te Lommel. Notae Praehistoricae, 23, 33-37.

De Bie, M., \& Van Gils, M. (2004). Steentijdsites op de Maatheide te Lommel: Archeologisch waarderingsonderzoek 2003.

De Bie, M., \& Van Gils, M. (2006). Les habitats des groupes à Federmesser (azilien) dans le Nord de la Belgique. Bulletin de la Société préhistorique française, 103(4), 781-790. doi:10.3406/bspf.2006.13505

De Bie, M., \& Van Gils, M. (2009). Mesolithic settlement and land use in the Campine region (Belgium). Mesolithic Horizons. papers presented at the Seventh International Conference on the Mesolithic in Europe, Belfast 2005, 282-287.

De Bie, M., Van Gils, M., \& Deforce, K. (2009). Human occupation in a Late Glacial landscape: the Federmessergruppen site complex at Lommel Maatheide (Belgium). In Humans, environment and chronology of the Late Glacial of the North European Plain. Proceedings of Workshop 14 (Commission XXXII) of the 15th U.I.S.P.P. Congress, Lisbon, September 2006 (pp. 77-87). 
de la Peña, P., Taipale, N., Wadley, L., \& Rots, V. (2018). A techno-functional perspective on quartz micro-notches in Sibudu's Howiesons Poort indicates the use of barbs in hunting technology. Journal of Archaeological Science, 93, 166-195. doi:10.1016/j.jas.2018.03.001

Derese, C., Vandenberghe, D. A. G., Van Gils, M., Mees, F., Paulissen, E., \& Van den haute, P. (2012). Final Palaeolithic settlements of the Campine region (NE Belgium) in their environmental context: Optical age constraints. Quaternary International, 251, 7-21. doi:10.1016/j.quaint.2011.03.023

Fackler, M. L., \& Malinowski, J. A. (1985). The wound profile: A visual method for quantifying gunshot wound components. Journal of Trauma - Injury, Infection and Critical Care, 25(6), 522. doi:10.1097/00005373-19823

000-00009

Fullagar, R. (2006). Residues and use-wear. In J. Balme \& A. Paterson (Eds.), Archaeology in practice: A student guide to archaeological analyses. (pp. 207-234). Wiley \& Sons.

Fullagar, R., Field, J., Denham, T., \& Lentfer, C. (2006). Early and mid Holocene tool-use and processing of taro (Colocasia esculenta), yam (Dioscorea sp.) and other plants at Kuk Swamp in the highlands of Papua New Guinea. Journal of Archaeological Science, 33(5), 595-614. doi:10.1016/j.jas.2005.07.020

Fullagar, R., \& Matheson, C. (2014). Stone tool usewear and residue analysis. In (C. Smith, Ed.)Encyclopedia of Global Archaeology. doi:10.1007/978-3-319-51726-1

Geerts, F. (1984). The Caris collection of Lommel. Notae Praehistoricae, 4(4), 17-22.

Geerts, F., Van Gils, M., \& De Bie, M. (2008). Federmessersites te Lommel - Maatheide (prov. Limburg, B). De opgravingscampagne van 2008. Notae Praehistoricae, 28, 43-45.

Genevois, J. (2019). Étude fonctionnelle de l'outillage lithique d'un site du Paléolithique supérieur: Tongres-Plinius.

Gero, J. M. (1978). Summary of Experiments to Duplicate Post-Excavational Damage to Tool Edges. Lithic Technology, 7(2), 34-34. doi:10.1080/01977261.1978.11754439

Grace, R. (1990). The limitations and applications of use wear analysis. Archaeological Studies Uppsala University - Institute of North European Archaeology, 14, 9-14.

Gron, O., \& Kuznetsov, O. (2004). What is a hunter-gatherer settlement? An ethno-archaeological and interdisciplinary approach. Section 7 Le Mesolithique/The Mesolithic.

Guéret, C. (2017). Retoucher, pour quoi faire?: réflexions fonctionnelle et méthodologiques sur la place occupée par l'outillage brut dans l'économie du premier Mésolithique en Europe du Nord-Ouest. Bulletin de la Société préhistorique française, 114(2), 339-370. doi:10.3406/bspf.2017.14776

Guéret, C., Gassin, B., Jacquier, J., \& Marchand, G. (2014). Traces of plant working in the Mesolithic shell midden of Beg-an-Dorchenn (Plomeur, France). Mesolithic Miscellanay, 22(3), 2-15.

Hamal-Nandrin, J., Servais, J., \& Louis, M. (1935). Nouvelle contribution à l'étude du préhistorique dans la Campine limbourgeoise (Belgique). Bulletin de la Société préhistorique de France, 32(3), 175-203. doi:10.3406/bspf.1935.6235

Hardy, B. (2004). Neanderthal behaviour and stone tool function at the Middle Palaeolithic site of La Quina, France. Antiquity, 78(301), 547-565. doi:10.1017/S0003598X00113213

Hayes, E., Cnuts, D., Lepers, C., \& Rots, V. (2017). Learning from blind tests: Determining the function of experimental grinding stones through use-wear and residue analysis. Journal of 
Archaeological Science: Reports, 11, 245-260. doi:10.1016/j.jasrep.2016.12.001

Hayes, E., Cnuts, D., \& Rots, V. (2019). Integrating SEM-EDS in a sequential residue analysis protocol: Benefits and challenges. Journal of Archaeological Science: Reports, 23(October 2018), 116-126. doi:10.1016/j.jasrep.2018.10.029

Hayes, E., \& Rots, V. (2019). Documenting scarce and fragmented residues on stone tools: an experimental approach using optical microscopy and SEM-EDS. Archaeological and Anthropological Sciences, 11(7), 3065-3099. doi:10.1007/s12520-018-0736-1

Hedges, R. E. M. (2002). Bone diagenesis: an overview of processes. Archaeometry, 44(3), 319328. doi:10.1111/1475-4754.00064

High, K., Milner, N., Panter, I., \& Penkman, K. E. H. (2015). Apatite for destruction: Investigating bone degradation due to high acidity at Star Carr. Journal of Archaeological Science, 59, 159168. doi:10.1016/j.jas.2015.04.001

Hurcombe, L. M. (2008). Looking for prehistoric basketry and cordage using inorganic remains: the evidence from stone tools. In Prehistoric technology 40 years later: functional studies and the Russian legacy (Vol. 40, pp. 205-216).

Jacquier, J. (2014). Analyse fonctionnelle des outillages lithiques et interprétations socioéconomiques du statut des sites tardiglaciaires du Buhot à Calleville (Eure) et de la Fosse à Villiers-Charlemagne (Mayenne). Les groupes culturels de la transition Pléistocène-Holocène entre Atlantique et Adriatique: actes de la séance de la Société préhistorique française, Bordeaux, 24-25 mai 2012, 221-246.

Jensen, H. J. (1994). Flint tools and plant working: hidden traces of Stone Age technology: a use wear study of some Danish Mesolithic and TRB implements. doi:10.5860/choice.32-2305

Jussila, J. (2004). Preparing ballistic gelatine - Review and proposal for a standard method. Forensic Science International, 141(2-3), 91-98. doi:10.1016/j.forsciint.2003.11.036

Kamminga, J. (1979). The Nature of Use-Polish and Abrasive Smoothing on Stone tools. Lithic UseWear Analysis, 143-158.

Keeley, L. H. (1980). Experimental Determination of Stone Tools Uses: A microwear analysis. Chicago and London: University of Chicago Press.

Lampert, R. J., \& Sim, R. (1986). Residues on Artefacts: Implications for Handling and Storage. Australian Archaeology, 22(22), 157-159. doi:10.2307/40286586

Langejans, G. (2010). Remains of the day-preservation of organic micro-residues on stone tools. Journal of Archaeological Science, 37(5), 971-985. doi:10.1016/j.jas.2009.11.030

Langenheim, J. J. H. (2003). Plant resins: chemistry, evolution, ecology and ethnobotany. Portland, Cambridge: Timber press.

Lepers, C., \& Rots, V. (2020). The important role of bow choice and arrow fletching in projectile experimentation. A ballistic approach. Journal of Archaeological Science: Reports, 34. doi:10.1016/j.jasrep.2020.102613

Levi Sala, I. (1988). Processes of polish formation on flint tool surface. In Industries lithiques. Tracéologie et technologie (pp. 83-97).

Michel, M., Cnuts, D., \& Rots, V. (2019). Freezing in-sight: the effect of frost cycles on use-wear and residues on flint tools. Archaeological and Anthropological Sciences, 11(10), 5423-5443. doi:10.1007/s12520-019-00881-w

Moss, E. H. (1983). The Functional Analysis of Flint Implements: Pincevent and Pont d'Ambon : two case studies from the French Final Palaeolithic. The Functional Analysis of Flint Implements: 
Pincevent and Pont d'Ambon : two case studies from the French Final Palaeolithic (Vol. 177). Ann Arbor, MI: University of Michigan Press. doi:10.30861/9780860542278

Newcomer, M. H. (1976). Spontaneous retouch. 2nd International Symposium on Flint, Staringia, 3(figure 1), 62-64.

Odell, George H. (1981). The Morphological Express at Function Junction: Searching for Meaning in Lithic Tool Types. Journal of Anthropological Research, 37(4), 319-342. doi:10.1086/jar.37.4.3629831

Odell, George Hamley, \& Odell-Vereecken, F. (1980). Verifying the Reliability of Lithic Use-Wear Assessments by "Blind Tests": The Low-Power Approach. Journal of Field Archaeology, 7(1). doi:10.2307/529584

Osipowicz, G. (2019). Plant processing in the Late Mesolithic Poland: in search for function of the mysterious 'curved knives.' Archaeological and Anthropological Sciences, 11(7), 3613-3628. doi:10.1007/s12520-019-00784-w

Pedergnana, A., Asryan, L., Fernández-Marchena, J. L., \& Ollé, A. (2016). Modern contaminants affecting microscopic residue analysis on stone tools: A word of caution. Micron, 86, 1-21. doi:10.1016/j.micron.2016.04.003

Pedergnana, A., \& Ollé, A. (2017). Building an Experimental Comparative Reference Collection for Lithic Micro-Residue Analysis Based on a Multi-Analytical Approach. Journal of Archaeological Method and Theory. doi:10.1007/s10816-017-9337-z

Plisson, H. (1985). Etude fonctionnelle d'outillages lithiques préhistoriques par l'analyse des microusures : recherche méthodologique et archéologique. Université de Paris I, thèse de doctorat.

Plisson, H. (2005). Examen traceologique des pointes aziliennes du Bois-Ragot. Mémoire XXXVIII de la Société préhistorique française, Mémoire XX, 183-189.

Plisson, H., \& Mauger, M. (1988). CHEMICAL AND MECHANICAL ALTERATfON OF MICROWEAR POLISHES AN EXPERIMENTAL APPROACH. Helinium, XXVII(1), 3-16.

Plisson, H., \& Van Gijn, A. (1989). La tracéologie: mode d'emploi. L'Anthropologie.

Regert, M. (2004). Investigating the history of prehistoric glues by gas chromatography-mass spectrometry. Journal of separation science, 27(3), 244-54. doi:10.1002/jssc.200301608

Rots, V. (2002). Hafting traces on flint tools: possibilities and limitations of macro-and microscopic approaches. KU Leuven, Leuven, Belgium.

Rots, V. (2003). Towards an understanding of hafting: the macro-and microscopic evidence. Antiquity, 77(298), 805-815.

Rots, V. (2010a). Prehension and hafting traces on flint tools: a methodology. Leuven: Universitaire Pers Leuven.

Rots, V. (2010b). Un tailleur et ses traces. Traces microscopiques de production: programme expérimental et potentiel interprétatif. Bulletin de la Société Royale Belge d'Etudes Géologiques et Archéologiques. Les Chercheurs de la Wallonie, hors-série, 51-67.

Rots, V. (2021). TRAIL: An Experimental Trace and Residue Reference Library for the functional analysis of stone tools in Liège. OSF Preprints, April 26. doi:10.31219/osf.io/jsak6

Rots, V., Hayes, E., Cnuts, D., Lepers, C., \& Fullagar, R. (2016). Making sense of residues on flaked stone artefacts: Learning from blind tests. PLOS ONE, 11(3), e0150437. doi:10.1371/journal.pone.0150437

Rots, V., Pirnay, L., Pirson, P., \& Baudoux, O. (2006). Blind tests shed light on possibilities and limitations for identifying stone tool prehension and hafting. Journal of Archaeological 
Science, 33(7), 935-952. doi:10.1016/j.jas.2005.10.018

Rots, V., \& Plisson, H. (2014). Projectiles and the abuse of the use-wear method in a search for impact. Journal of Archaeological Science, 48, 154-165. doi:10.1016/j.jas.2013.10.027

Rottländer, R. (1975). The formation of patina on flint. Archaeometry, 17(1), 106-110. doi:10.1111/j.1475-4754.1975.tb00120.x

Sala, I. L. (1986). Usewear and Post- Depositional Surface Modification : A Word of Caution. Journal of Archaeological Science, 13, 229-244. doi:10.1016/S0022-5347(01)64159-4

Semenov, S. (1964). Prehistoric technology. London: Cory. Adams \& mackay.

Sobkowiak-Tabaka, I., \& Kufel-Diakowska, B. (2019). The shining piece of the puzzle: evidence of plant use in the Late Palaeolithic. Archaeological and Anthropological Sciences, 11(4), 13731389. doi:10.1007/s12520-018-0604-z

Stapert, D. (1976). Some natural surface modifications on flint. Palaeohistoria, 18, 7-41.

Stordeur, D. (1987). La main et l'outil : manches et emmanchements préhistoriques : table ronde CNRS tenue à Lyon du 26 au 29 novembre 1984. Travaux de la Maison de l'Orient ; 15.

Taipale, N. (2020). Hafting as a flexible strategy: variability in stone tool use and hafting at three european upper palaeolithic sites.

Taipale, N., \& Rots, V. (2019). Breakage, scarring, scratches and explosions: understanding impact trace formation on quartz. Archaeological and Anthropological Sciences, 11(6), 3013-3039. doi:10.1007/s12520-018-0738-z

Taipale, N., \& Rots, V. (2021). Every hunter needs a knife: Hafted butchering knives from Maisières-Canal and their effect on lithic assemblage characteristics. Journal of Archaeological Science: Reports. doi:10.1016/j.jasrep.2021.102874

Thiébaut, C. (2007). Les pièces encochées au Paléolithique moyen et les pseudo-outils : peut-on les distinguer ? In Un siècle de construction du discours scientifique en préhistoire. Volume III (pp. 201-216).

Tomasso, A., \& Rots, V. (2021). Looking into Upper Paleolithic gear: The potential of an integrated techno-economic approach. Journal of Anthropological Archaeology, 61. doi:10.1016/j.jaa.2020.101240

Tomasso, A., Rots, V., Purdue, L., Beyries, S., Buckley, M., Cheval, C., et al. (2018). Gravettian weaponry: 23,500-year-old evidence of a composite barbed point from Les Prés de Laure (France). Journal of Archaeological Science, 100(May), 158-175. doi:10.1016/j.jas.2018.05.003

Tomasso, S. (2021). What is the new Aterian? A functional view on tool, use, hafted stone tool, technologies and assemblage variability at Ifri n'Ammar within the context of the Northwest African Middle Stone Age. Université of Liège.

Tringham, R., Cooper, G., \& Odell, G. (1974). Experimentation in the formation of edge damage: a new approach to lithic analysis. Journal of Field ..., 1(1), 171-196.

Tydgadt, L. (2019). Leave no stone unturned, Étude fonctionnelle des assemblages lithiques protohistoriques de Wanze et Harmignies.

Van Gijn, A. (1990). Functional Differentiation of Late Neolithic Settlements in the Dutch Coastal Area. In H. Knutsson, J. Taffinder, B. Gräslund, \& K. Knutsson (Eds.), The interpretive possibilities of microwear studies. Proceedings of the international conference of microwear analysis. Uppsala 15-17 February 1989 (pp. 77-87).

Van Gijn, A., \& Mazzucco, N. (2013). Domestic activities at the Linear Pottery site of Elsloo 
(Netherlands): a look from under the microscope. Internationale Archäologie.

Van Gils, M., \& De Bie, M. (2004). Federmessersites te Lommel-Maatheide (Limburg), Opgravingscampagne 2004. Notae Praehistoricae, 24, 89-94.

Van Gils, M., \& De Bie, M. (2005). Federmessersites te Lommel-Maatheide. Opgravingscampagne 2005. Notae Praehistoricaete Praehistorica, 25, 109-112.

Van Gils, M., \& De Bie, M. (2008). Les occupations tardiglaciaires et postglaciaires du nord de la Belgique : modalités d'occupation du territoire. In Le début du Mésolithique en Europe du Nord-Ouest. Actes de la table ronde d'Amiens (Vol. 27, p. 195). doi:10.7202/1035811ar

Van Noten, F. L. (1978). Les chasseurs de Meer (Vol. 76). Brugge: Brugge : De Tempel.

Vaughan, P. C. (1985). Use-wear analysis of flaked stone tools. Tucson: University of Arizona Press.

Verheyleweghen, J. (1956). Le Paléolithique final de culture périgordienne du gisement préhistorique de Lommel (Province de Limbourg, Belgique). Bulletin de la Société Royale Belge d'Anthropologie et de Préhistoire (Vol. 67).

Vermeersch, P. M. (1975). Haltplaats van het Tjongeriaan te Lommel-Werkplaatsen. Archeologie, 2, 64-67.

Vinet, L., \& Zhedanov, A. (2011). A "missing" family of classical orthogonal polynomials. Journal of Physics A: Mathematical and Theoretical. 